Anales de Geografía de la Universidad Complutense ISSN: 0211-9803

https://dx.doi.org/10.5209/aguc.79344

\title{
La enseñanza del riesgo de inundación en Bachillerato mediante Sistemas de Información Geográfica (SIG). El ejemplo del PATRICOVA en la Comunidad Valenciana (España) ${ }^{1}$
}

\author{
Álvaro-Francisco Morote Seguido²; Jorge Olcina Cantos ${ }^{3}$ \\ Recibido: 6 de mayo del 2021 / Enviado a evaluar: 20 de junio del 2021 / Aceptado: 10 de diciembre del 2021
}

\begin{abstract}
Resumen. Las inundaciones son el riesgo natural de mayor impacto económico y que causa más víctimas humanas en España, con particular incidencia en las regiones del litoral mediterráneo. El objetivo de este trabajo es llevar a cabo diferentes propuestas para trabajar el riesgo de inundación a partir del visor SIG que ofrece el Plan de Acción Territorial sobre prevención del Riesgo de Inundación en la Comunidad Valenciana (PATRICOVA). Estas propuestas están orientadas al curso de $2^{\circ}$ de Bachillerato (asignatura optativa de Geografía) y lo que se pretende es fomentar entre el alumnado, capacidades para interpretar el territorio, especialmente su entorno más inmediato en el proceso de aprendizaje. Con ello, se pretende que el alumnado logre un mejor conocimiento de estos fenómenos extremos por parte de la sociedad, lo que permitirá conseguir territorios y una sociedad más resiliente ante los eventos extremos, como medida de adaptación ante el proceso actual de calentamiento climático. Palabras clave: Riesgo de inundación; propuestas; enseñanza; Bachillerato; cambio climático.
\end{abstract}

[en] Teaching of flood risk in Baccalaureate through Geographic Information Systems (GIS). The example of PATRICOVA in the Valencian Community (Spain)

\begin{abstract}
Floods are the natural hazard with the greatest economic impact and that causes most deaths in Spain, with particular incidence in the Mediterranean coast. The objective of this work is to carry out different proposals to teach the risk of flooding from the GIS viewer offered by the Territorial Action Plan on prevention of Flood Risk in the Valencian Community (PATRICOVA). These proposals are aimed at the 2nd year of Baccalaureate (optional subject of Geography). And what is intended is to
\end{abstract}

1 Esta investigación se inserta en el proyecto "Las representaciones sociales de los contenidos escolares en el desarrollo de las competencias docentes" (PGC2018-094491-B-C32) financiado por el Ministerio de Ciencia, Innovación y Universidades y cofinanciado con fondos FEDER de la UE.

2 Departamento Didáctica de las Ciencias Experimentales y Sociales. Universidad Valencia (España).

E-mail: alvaro.morote@uv.es

3 Departamento Análisis Geográfico Regional y Geografía Física. Universidad de Alicante (España).

E-mail: jorge.olcina@ua.es 
promote among students, skills to interpret the territory, especially their immediate environment in the learning process. With this, it is intended that students achieve a better knowledge of these extreme phenomena by society. This action will allow them to achieve territories and a society more resilient to extreme events, as a measure of adaptation to the current process of climate warming.

Keywords: Risk of flooding; proposals; teaching; Baccalaureate; climate change.

[fr] L'enseignement du risque inondation au Baccalauréat à travers les Systèmes d'Information Géographique. L'exemple de PATRICOVA dans la Communauté Valencienne (Espagne)

Résumé. Les inondations sont le risque naturel avec le plus impact économique et qui cause le plus de victimes humaines en Espagne, avec une incidence particulière dans les régions de la côte méditerranéenne. L'objectif de ce travail est de réaliser différentes propositions pour travailler sur le risque d'inondation à partir du visualiseur SIG offert par le Plan d'action territorial sur la prévention du risque d'inondation dans la Communauté valencienne (PATRICOVA). Ces propositions s'adressent à la 2e année du Baccalauréat (matière optionnelle de Géographie) et ce qui est destiné est de promouvoir chez les étudiants, les compétences pour interpréter le territoire, notamment leur environnement immédiat dans le processus d'apprentissage. Avec cela, il est prévu que les étudiants acquièrent une meilleure connaissance de ces phénomènes extrêmes par la société, ce qui leur permettra d'atteindre des territoires et une société plus résilients aux événements extrêmes, comme mesure d'adaptation au processus actuel de réchauffement climatique.

Mots-clés: Risques d'inondation ; propositions; enseignement; Baccalauréat; changement climatique.

Cómo citar. Morote Seguido, A.F.; Olcina Cantos, J. (2021): La enseñanza del riesgo de inundación en Bachillerato mediante Sistemas de Información Geográfica (SIG). El ejemplo del PATRICOVA en la Comunidad Valenciana (España). Anales de Geografía de la Universidad Complutense, 41(2), 431-461.

Sumario. 1. Introducción. 2. Fuentes y metodología. 2.1. Currículo y normativa sobre el cambio climático en materia escolar. 2.2. El PATRICOVA. Un recurso SIG con gran potencial didáctico para la Geografía escolar. 3. Algunas propuestas para la enseñanza del riesgo de inundación en el aula. El caso de la Vega Baja del Segura (Alicante). 3.1. La Vega Baja del Segura. Un territorio de riesgo. 3.1.1. Características climáticas. Un territorio de extremos. 3.1.2. Antropización del territorio basado en el turismo residencial y la agricultura de regadío. 3.1.3. El río Segura. Un curso fluvial de comportamiento extremo. 3.1.4. El episodio de lluvias torrenciales y graves inundaciones del 12-13 de septiembre de 2019. Un fenómeno reiterado en la comarca. 3.2. Propuesta de actividades para la enseñanza del riesgo de inundación en la comarca de la Vega Baja del Segura (Comunidad Valenciana). 3.2.1. Actividad 1. Diagnóstico territorial del área de estudio. Una región donde el riesgo de inundación constituye un rasgo estructural. 3.2.2. Actividad 2. Análisis del episodio del 12-13 de septiembre de 2019. Causas y consecuencias. 4. Discusión y conclusiones. 5. Recursos en línea referenciados para usar en el Aula. 6. Referencias bibliográficas

\section{Introducción}

En Europa, los riesgos naturales de carácter atmosférico en las últimas décadas están generando un volumen creciente de pérdidas económicas y humanas (Pérez-Morales et al., 2021). A escala mundial, según el Centre for Research on the Epidemiology of Disasters (CRED, 2019), estos fenómenos son considerados como el riesgo natural más frecuente (con un porcentaje del 43\% sobre el total de episodios anuales ocurridos) y el que afecta a más personas, tanto el número de víctimas como en 
afectados. Y, según las previsiones, a nivel mundial, se estima que en 2050 los damnificados anuales por las inundaciones puedan ascender a 300.000 y llegar a casi 400.000 en los años ochenta del actual siglo XXI (Intergovernmental Panel on Climate Change, IPCC, 2014). En Europa la EM-DAT (2021) ha registrado que entre el periodo 2000-2020, 1.933 personas han perdido la vida debido a 400 episodios de inundaciones, mientras que 6,8 millones de personas se vieron afectadas. Para el caso español, como ha puesto de manifiesto Olcina (2018), 2 millones de personas viven en lugares de alto riesgo de inundación. Desde 2000 a 2019, se han registrado 209 fallecimientos por inundaciones en España, lo que representa el $20 \%$ del total de víctimas por peligros naturales en este intervalo, siendo las regiones del litoral mediterráneo las más afectadas por estos eventos (Ministerio del Interior, 2020).

En la Comunidad Valenciana, espacio de análisis principal del presente trabajo, el Plan de Acción de Acción Territorial sobre prevención del Riesgo de Inundación en la Comunidad Valenciana (PATRICOVA), señala que 600.000 habitantes (el 12\% de la población de la región) residen en zonas inundables. De ellas, 30.000 tienen su residencia en zonas con un riesgo elevado. En cuanto al ámbito educativo, un dato que pone de manifiesto la importancia de tener en cuenta estos fenómenos es que oficialmente, 327 centros educativos están afectados por este riesgo (tienen algún elemento-construcción dentro de un área inundable), y destacando que 6 centros escolares se localizan en áreas de riesgo "muy alto" (PATRICOVA, 2015).

Una cuestión clave en el análisis de riesgo es el reconocimiento inicial de que la sociedad actual es una sociedad del riesgo (Adam et al., 2000; Giddens, 1977; White, 1974). El riesgo integra dos variables principales, como señalan Wisner et al. (2004): 1) el factor físico o peligro (P); y 2) el factor humano, o lo que es lo mismo, la vulnerabilidad (V). Por lo tanto, $\mathrm{R}=\mathrm{P} \cdot \mathrm{V}$. Por su parte, Ward et al. (2020) añaden a esta ecuación el factor exposición o territorio de afectación de un episodio extremo, que añade el componente espacial del análisis de riesgo. En el análisis y enseñanza del riesgo, no hay que olvidar el rol que desempeña el ser humano y como este puede incidir en su incremento (Morote y Pérez-Morales, 2019).

En el ámbito educativo, para explicar estos fenómenos, además, se debe contemplar la incidencia actual y futura del cambio climático ya que como ponen de manifiesto los principales informes internacionales, las inundaciones serán en el futuro más intensas y frecuentes (IPCC, 2018). Sin embargo, su enseñanza es una tarea compleja como indica Olcina (2017). Autores como Ozdem et al. (2014) argumentan que a la comunidad científica incluso le resulta controvertido tener una explicación sencilla de la evolución de los rasgos climáticos a escala planetaria y su estado actual debido a la amalgama de factores que intervienen. A estos factores habría que añadir: 1) los estereotipos y noticias falsas creadas por parte de los medios de comunicación (Brisman, 2018); 2) el escaso rigor científico sobre esta temática que se puede observar en los manuales escolares (Morote y Olcina, 2020); y 3) la escasa formación del actual profesorado (Morote et al., 2021).

La educación es una de las acciones más importantes para hacer frente al cambio climático y a los riesgos naturales; sin embargo, ha sido una cuestión escasamente contemplada en la acción docente (Morote y Olcina, 2020; 2021). El impulso de la 
enseñanza del cambio climático y de los peligros atmosféricos asociados ha sido puesto de manifiesto en el $5^{\circ}$ Informe de Cambio Climático del IPCC (IPCC, 2014). Por tanto, es necesario impulsar una enseñanza rigurosa sobre los riesgos naturales. Esta necesidad ha sido incluso avalada en los últimos años por las Naciones Unidas, con su impulso decidido por la educación en materias de cambio climático y de extremos asociados como acción básica para el logro de los denominados Objetivos de Desarrollo Sostenible (ODS) -Agenda 2030-, concretamente con el objetivo $\mathrm{n}^{\mathrm{o}} 13$ “Acción por el clima" (United Nations, 2015).

En el ámbito internacional diferentes investigaciones en la última década han puesto de manifiesto la importancia del estudio del riesgo de inundación en todos los niveles educativos (Ahmad y Numan, 2015; Duman, 2018; McWhirter y Shealy, 2018). Algunos de estos trabajos se han realizado en EE.UU. (Gary et al., 2014; Lee et al., 2019), Europa (Bosschaart et al., 2016; Bricelj, 2013; Lechowicz y Nowacki, 2014; McEwen et al., 2014; Williams et al., 2017), Asia (Chang y Pascua, 2017; Chang et al., 2018; How et al., 2017; Irvine et al., 2015; Meera et al., 2016; Shah et al., 2020; Zhong et al., 2021) o Africa (Mudavanhu, 2015). En España, la mayoría de la producción científica sobre este tema (desde la didáctica) se ha realizado en el campo de las Ciencias Experimentales y Naturales (Díez-Herrero, 2015; Garzón et al., 2009). Sin embargo, desde la Didáctica de la Geografía y/o Ciencias Sociales no es habitual encontrar este tipo de publicaciones (Cuello, 2018; Cuello y García, 2019; Ollero, 1997). Para el caso de la región valenciana, recientemente se han llevado a cabo algunos trabajos sobre las representaciones sociales del futuro profesorado en Educación Primaria (Morote y Hernández, 2020; 2021; Morote y Souto, 2020) así como propuestas didácticas sobre salidas de campo (Morote, 2017; Morote y PérezMorales, 2019).

El interés por el análisis de esta cuestión en el ámbito escolar se debe a varios motivos: 1) se trata de una temática geográfica (riesgos naturales) que debe enseñarse en la asignatura de Geografía de $2^{\circ}$ de Bachillerato según pone de manifiesto el actual currículo nacional (Real Decreto 1105/2014, de 26 de diciembre) y autonómico (Decreto 87/2015, de 5 de junio); 2) la región valenciana (ámbito de estudio) se ha convertido en una región-riesgo, tanto por sus condiciones atmosféricas en el contexto del cambio climático actual, como por el incremento de la urbanización (impermeabilización) y ocupación de zonas inundables; 3 ) la percepción errónea de la sociedad sobre su supuesto dominio de la naturaleza que permitiría alcanzar el "riesgo 0 " ante los peligros naturales, cuestión que se ha demostrado totalmente improbable (Olcina, 2017); y 4) los efectos del cambio climático prevén que estos fenómenos atmosféricos extremos (como las inundaciones) serán en el futuro más intensos y frecuentes, como de hecho ya se está manifestando (Muñoz et al., 2020). Por tanto, la educación es decisiva para formar a las cohortes más jóvenes en el funcionamiento de estos fenómenos extremos que generan elevados daños económicos y pérdida de vidas humanas.

El objetivo de este trabajo es aportar diferentes propuestas para trabajar el riesgo de inundación a partir del uso de Sistemas de Información Geográfica (SIG), en concreto mediante el empleo del visor que ofrece el Plan de Acción Territorial sobre 
prevención del riesgo de inundación en la Comunidad Valenciana (PATRICOVA). Estas propuestas están orientadas a la asignatura de Geografía (optativa) de $2^{\circ}$ de Bachillerato y, lo que se busca es fomentar entre el alumnado, capacidades para interpretar el territorio, especialmente su entorno más inmediato en el proceso de aprendizaje. Con ello, se pretende que el alumnado logre un mayor conocimiento de estos fenómenos extremos por parte de la sociedad, lo que permitirá conseguir territorios y sociedades más preparadas ante los eventos extremos, como medida de adaptación ante el proceso actual de calentamiento climático.

\section{Fuentes y metodología}

\subsection{Currículo y normativa sobre el cambio climático en materia escolar}

Para llevar a cabo los objetivos propuestos, en primer lugar, se ha consultado el currículo nacional vigente de Educación Secundaria Obligatoria y del Bachillerato (Real Decreto 1105/2014, de 26 de diciembre) (ver Tabla 1). En España, cabe indicar que los contenidos docentes están transferidos a las comunidades autónomas, quienes se encargan de concretarlos en un currículo propio. Aunque en este trabajo se propone un área concreta del territorio valenciano (comarca de la Vega Baja), lo que se pretende es que sea un modelo y guía para poder realizar en otros ámbitos. Por ello, para el diseño de las actividades se ha tenido en cuenta la normativa nacional. Se trata de una propuesta general que, incluso puede ser adaptada a la Educación Secundaria e incluso Educación Primaria, especialmente para el $3^{\text {er }}$ ciclo (cursos $5^{\circ}$ y $6^{\circ}$ ). Y, si los medios lo permiten (existencia de cartografía de riesgo), también puede servir para el ámbito internacional. Es, por tanto, cuestión de cada docente, adaptarla a su curso y región objeto de trabajo.

Tabla 1. Contexto curricular de la asignatura de Geografía de $2^{\circ}$ de Bachillerato para la enseñanza de los riesgos de inundación

\begin{tabular}{|c|c|c|c|}
\hline & Contenidos & Criterios de evaluación & Estándares de aprendizaje \\
\hline $\begin{array}{c}\text { Bloque 1. "La } \\
\text { Geografía y el } \\
\text { estudio del espacio } \\
\text { geográfico" }\end{array}$ & $\begin{array}{l}\text {-Las técnicas cartográficas: } \\
\text { Planos y mapas, sus } \\
\text { componentes y análisis. } \\
\text {-La representación gráfica } \\
\text { del espacio geográfico a } \\
\text { distintas escalas. Obtención e } \\
\text { interpretación de la } \\
\text { información cartográfica. }\end{array}$ & 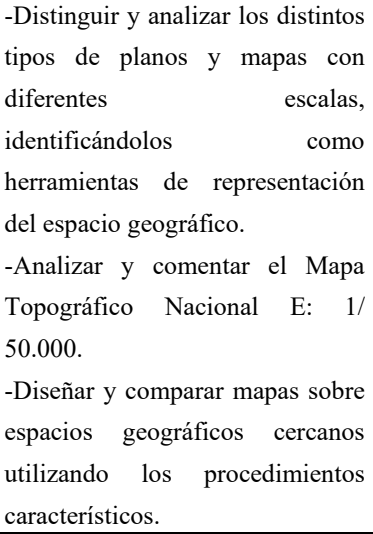 & $\begin{array}{l}\text {-Utiliza adecuadamente las } \\
\text { herramientas características de } \\
\text { la ciencia geográfica. } \\
\text {-Extrae información del Mapa } \\
\text { Topográfico mediante los } \\
\text { procedimientos de trabajo del } \\
\text { geógrafo. } \\
\text {-Sobre mapas y planos de } \\
\text { diferentes escalas extrae la } \\
\text { información. } \\
\text {-Analiza y extrae conclusiones } \\
\text { de la observación de un plano y } \\
\text { mapa, comentando las }\end{array}$ \\
\hline
\end{tabular}




\begin{tabular}{|c|c|c|c|}
\hline & & $\begin{array}{l}\text {-Buscar, seleccionar y elaborar } \\
\text { información de contenido } \\
\text { geográfico obtenida de fuentes } \\
\text { diversas presentándola de forma } \\
\text { adecuada. }\end{array}$ & $\begin{array}{l}\text { características del espacio } \\
\text { geográfico. }\end{array}$ \\
\hline $\begin{array}{l}\text { Bloque 3. "La } \\
\text { diversidad } \\
\text { climática y la } \\
\text { vegetación" }\end{array}$ & $\begin{array}{l}\text {-Factores geográficos y } \\
\text { elementos del clima. } \\
\text {-Dominios climáticos } \\
\text { españoles: su problemática. }\end{array}$ & 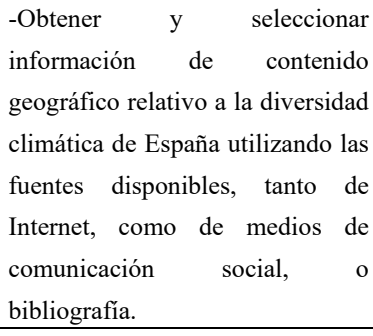 & $\begin{array}{l}\text {-Analiza cómo afecta a España } \\
\text { el cambio climático. } \\
\text {-Extrae conclusiones } \\
\text { medioambientales con el uso } \\
\text { de gráficas y estadísticas que } \\
\text { reflejan las lluvias torrenciales }\end{array}$ \\
\hline $\begin{array}{l}\text { Bloque 4. "La } \\
\text { Hidrografía" }\end{array}$ & $\begin{array}{l}\text {-El aprovechamiento de los } \\
\text { recursos hídricos: la } \\
\text { incidencia de la sequía y las } \\
\text { lluvias torrenciales. }\end{array}$ & $\begin{array}{l}\text {-Analizar el aprovechamiento de } \\
\text { los recursos hídricos en nuestro } \\
\text { país incluyendo las características } \\
\text { de sequía y lluvias torrenciales del } \\
\text { clima. }\end{array}$ & $\begin{array}{l}\text {-Sitúa en un mapa de la red } \\
\text { hidrográfica española los } \\
\text { grandes embalses. Deduce } \\
\text { consecuencias analizando } \\
\text { también las características } \\
\text { climáticas. } \\
\text {-Analiza y comenta gráficas y } \\
\text { estadísticas que reflejan las } \\
\text { épocas de sequía en relación } \\
\text { con un mapa de tipos de } \\
\text { regímenes fluviales de los ríos } \\
\text { de la península. }\end{array}$ \\
\hline $\begin{array}{c}\text { Bloque 5. "Los } \\
\text { paisajes naturales } \\
\text { y las } \\
\text { interrelaciones } \\
\text { naturaleza- } \\
\text { sociedad" }\end{array}$ & $\begin{array}{l}\text {-La influencia del medio en } \\
\text { la actividad humana. } \\
\text {-Los medios humanizados y } \\
\text { su interacción en el espacio } \\
\text { geográfico. } \\
\text {-Los paisajes culturales. }\end{array}$ & $\begin{array}{l}\text {-Describir los espacios } \\
\text { humanizados enumerando sus } \\
\text { elementos constitutivos. } \\
\text {-Relacionar el medio natural con } \\
\text { la actividad humana describiendo } \\
\text { casos de modificación del medio } \\
\text { por el hombre. } \\
\text {-Obtener y seleccionar } \\
\text { información de contenido } \\
\text { geográfico relativo a los paisajes } \\
\text { naturales y las interrelaciones } \\
\text { naturaleza-sociedad utilizando } \\
\text { fuentes en las que se encuentre } \\
\text { disponible, tanto en Internet, } \\
\text { bibliografía o medios de } \\
\text { comunicación social. }\end{array}$ & $\begin{array}{l}\text {-Identifica y plantea los } \\
\text { problemas suscitados por la } \\
\text { interacción hombre-naturaleza } \\
\text { sobre los paisajes. } \\
\text {-Analiza algún elemento } \\
\text { legislador correctivo de la } \\
\text { acción humana sobre la } \\
\text { naturaleza. } \\
\text {-Selecciona y analiza noticias } \\
\text { periodísticas o imágenes en los } \\
\text { que se percibe la influencia del } \\
\text { medio en la actividad humana. } \\
\text {-Selecciona y analiza a partir } \\
\text { de distintas fuentes de } \\
\text { información noticias } \\
\text { periodísticas o imágenes en las } \\
\text { que se percibe la influencia del } \\
\text { hombre sobre el medio. }\end{array}$ \\
\hline
\end{tabular}

Fuente: Ministerio de Educación, Cultura y Deporte (2021). Elaboración propia. 
Para la elaboración de las propuestas de actividades aquí presentadas en relación con los riesgos de inundación se han tenido en cuenta los contenidos, criterios de evaluación y estándares de aprendizaje que incorpora el Real Decreto 1105/2014 (ver Tabla 1). En la asignatura de Geografía los contenidos vinculados con los riesgos de inundación se insertan en el Bloque 3 "La diversidad climática y la vegetación" y Bloque 4 "La Hidrografía" que, según se indica, aportan: la posibilidad de analizar y realizar interpretaciones globales, sistemáticas e integradas de la realidad territorial; e identificar las unidades territoriales, los paisajes, los resultados de la actividad humana para poder conocer y comprender el espacio. Cabe destacar la importancia que le da el currículo a la hora de tratar estos fenómenos ya que se puede interpretar que no sólo se contempla el factor climático (factor peligrosidad) sino también la componente humana (factor vulnerabilidad) como queda patente en el Bloque 5 "Los paisajes naturales y las interrelaciones naturaleza-sociedad". De este modo, la Geografía planteada en $2^{\circ}$ de Bachillerato tiene como finalidad fundamental dar una interpretación global e interrelacionada de cada fenómeno geográfico y ofrecer los mecanismos que sirvan para dar respuestas y explicaciones a los problemas que plantea el territorio español. En cuanto al recurso que se propone utilizar en este trabajo (visor del PATRICOVA), también cabe destacar que se insertaría en el Bloque 1 "La Geografía y el estudio del espacio geográfico" ya que en este se propone trabajar diferentes destrezas y competencias vinculadas con la interpretación cartográfica (ver Tabla 1).

Tabla 2. Puntos 1, 2 y 5 del Art. 31 de la Ley de Cambio Climático (2021)

Punto 1. El sistema educativo español promoverá la implicación de la sociedad española en las respuestas frente al cambio climático, reforzando el conocimiento sobre el cambio climático y sus implicaciones, la capacitación para una actividad técnica y profesional baja en carbono y resiliente frente al cambio del clima y la adquisición de la necesaria responsabilidad personal y social.

Punto 2. El Gobierno revisará el tratamiento del cambio climático y la sostenibilidad en el currículo básico de las enseñanzas que forman parte del Sistema Educativo de manera transversal, incluyendo los elementos necesarios para hacer realidad una educación para el desarrollo sostenible. Asimismo el Gobierno, en el ámbito de sus competencias, impulsará las acciones que garanticen la adecuada formación del profesorado en esta materia.

Punto 5. El Gobierno, tendrá en cuenta la influencia que tiene la educación informal junto a la educación formal y la educación no formal, y hará uso de ella para realizar campañas de sensibilización y concienciación hacia la ciudadanía sobre los efectos del cambio climático y sobre el impacto que tiene la actividad humana en él. Además, el Gobierno y las distintas Administraciones Públicas reconocerán y pondrán los medios y recursos necesarios para que las entidades puedan realizar actividades de educación no formal, entendiendo que es una vía más para promover la implicación de colectivos especialmente vulnerables como son la infancia y la juventud en la lucha contra el cambio climático.

Fuente: Gobierno de España (2021). 
También se ha consultado la reciente Ley española de Cambio Climático (aprobada en mayo de 2021) en el que, por vez primera, a nivel nacional, se dedica un apartado a la enseñanza del cambio climático (Título VIII "Educación, Investigación e Innovación en la lucha contra el cambio climático y la transición energética"). En esta apartado se recogen dos artículos: Art. 31. "Educación y capacitación frente al cambio climático" y Art. 32. "Investigación, desarrollo e innovación sobre cambio climático y transición energética". Respecto al primero, quedan recogidas diferentes motivaciones que justifican y motivan la realización del presente trabajo (ver Tabla 2).

\subsection{EI PATRICOVA. Un recurso SIG con gran potencial didáctico para la Geografía escolar}

El PATRICOVA es un plan de ordenación del territorio de carácter sectorial que tiene por objeto la reducción del riesgo de inundaciones en la Comunidad Valenciana. Esta región es uno de los territorios españoles con mayor grado de riesgo de inundación y uno de los más destacados de Europa, debido a: 1) la confluencia de una elevada peligrosidad natural (cursos fluviales de comportamiento torrencial, situaciones atmosféricas favorables al desarrollo de lluvias intensas, configuración de relieves proclive a los efectos de disparo del aire); y 2) una vulnerabilidad también importante, especialmente en la franja litoral, donde confluyen actividades económicas de valor comercial, trazado de infraestructuras de comunicación y ubicación de los principales núcleos urbanos (Olcina et al., 2018).

El PATRICOVA tiene su origen en los episodios de inundación sufridos en la Comunidad Valenciana en la década de los años ochenta del pasado siglo XX (1982, 1987, 1989). Los efectos de estos eventos extremos provocaron la elaboración de una primera cartografía de riesgo de inundación (aunque realmente de peligrosidad) en 1995, como paso previo a la elaboración de un plan de reducción del riesgo a partir de la planificación del territorio, acogido a la legislación valenciana de ordenación territorial de 1989 (Ley 6/1989), posteriormente modificada (Ley 5/2014., mod. Ley 1/2019). Este plan adoptó la figura de plan de acción territorial de carácter sectorial, como se ha señalado, con el objetivo de incorporar un conjunto de determinaciones urbanísticas y territoriales para la reducción del riesgo de inundación. La primera versión del PATRICOVA se aprobó en 2003, incluyendo junto a la cartografía de peligrosidad de inundaciones y las determinaciones urbanísticas, un conjunto de actuaciones de infraestructura hidráulica y de restauración hidrológico-forestal.

La aplicación del plan, desde entonces, mostró algunas carencias que motivaron una actualización y mejora en el año 2015. Esta nueva versión vigente ha incorporado algunas novedades dignas de mención. Por ejemplo, para el establecimiento de los 6 niveles de riesgo de inundación (de "muy alto" a "muy bajo") se ha incorporado, junto al mapa de peligrosidad de inundaciones, una cartografía de riesgo geomorfológico que tiene en cuenta el funcionamiento hidráulico en diferentes formas de relieve (principalmente ramblas y barrancos). En cuanto a la determinación de la peligrosidad de inundación, el PATRICOVA define estos 6 niveles a partir de 2 
variables: período de retorno y altura de la lámina de agua (ver Tabla 2). Esta combinación se basa en la idea de que los daños por una crecida fluvial aumentan de forma significativa cuando la lámina de agua supera los $80 \mathrm{~cm}$ (ver Figura 1).

Tabla 2. Niveles de peligrosidad del PATRICOVA (del 1 al 6)

\begin{tabular}{|c|c|c|}
\hline & $\begin{array}{c}\text { Altura de la lámina de } \\
\text { agua }(<\mathbf{8 0} \mathbf{~ c m})\end{array}$ & $\begin{array}{c}\text { Altura de la lámina de } \\
\text { agua }(>\mathbf{8 0} \mathbf{~ c m})\end{array}$ \\
\hline $\begin{array}{c}\text { Período de retorno } \\
<\mathbf{2 5} \text { años }\end{array}$ & 3 & 1 \\
\hline $\begin{array}{c}\text { Período de retorno } \\
\mathbf{2 5 - 1 0 0} \text { años }\end{array}$ & 4 & 2 \\
\hline $\begin{array}{c}\text { Período de retorno } \\
\mathbf{1 0 0 - 5 0 0} \text { años }\end{array}$ & 5 & 6 \\
\hline
\end{tabular}

Fuente: PATRICOVA (2015).

Asimismo, ha habido una actualización del factor humano (vulnerabilidad) en la determinación del riesgo a partir del estudio de las siguientes variables: 1) la población total del término municipal; 2) el peso de los sectores productivos (según el empleo total del municipio); 3) la proporción de población activa ligada a la agricultura; 4) el valor y la composición del parque de viviendas; 5) el porcentaje de la superficie afectada por la inundación; y 6) la densidad de la población.

Figura 1. Relación entre altura de la lámina de agua y porcentaje de daños registrados en una crecida fluvial según criterio utilizado en el PATRICOVA

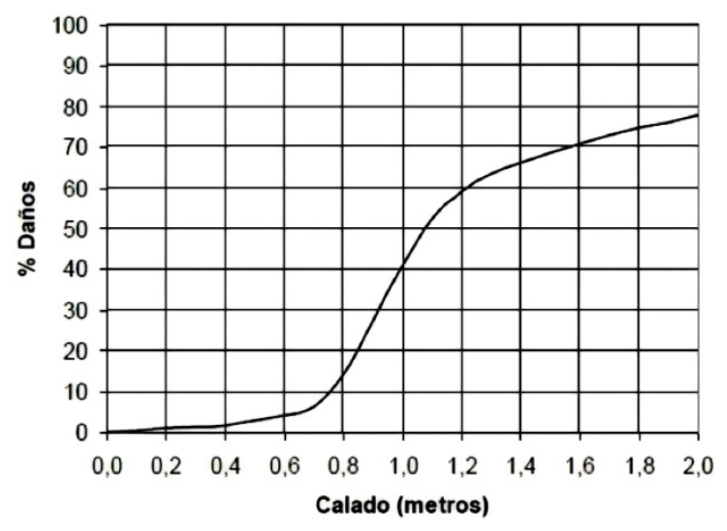

Fuente: PATRICOVA (2015). Elaboración propia.

La versión del PATRICOVA de 2015 resulta más completa a la hora de la determinación del riesgo de inundación, en virtud de los nuevos criterios incorporados (riesgo geomorfológico y vulnerabilidad) y de la mejora de la cartografía incorporada. Además, se ha incorporado un visor propio accesible desde el 
Instituto Cartográfico Valenciano (ICV) (https://visor.gva.es/visor/) para la consulta de la cartografía de inundación que permite descender a escalas de detalle para la planificación urbanística. Esto lo convierte en una herramienta de fácil acceso y de gran utilidad no sólo con finalidad territorial, sino que puede manejarse como recurso didáctico para la explicación en el aula de la temática del riesgo, en diferentes niveles educativos escolares y universitarios.

\section{Algunas propuestas para la enseñanza del riesgo de inundación en el aula. El caso de la Vega Baja del Segura (Alicante)}

En este trabajo se proponen dos actividades que están pensadas para desarrollarse durante 4 sesiones y con una duración de 55' cada una según establece el Real Decreto 1105/2014 (asignatura de Geografía de $2^{\circ}$ de Bachillerato). En cuanto al marco geográfico se ha propuesto la comarca alicantina de la Vega Baja (ver Figura 2), y se ha diseñado una propuesta curricular acorde con la etapa cognitiva, currículo nacional (RD 1105/2014) y área de estudio.

Figura 2. Localización del área de estudio (comarca de la Vega Baja, Alicante)

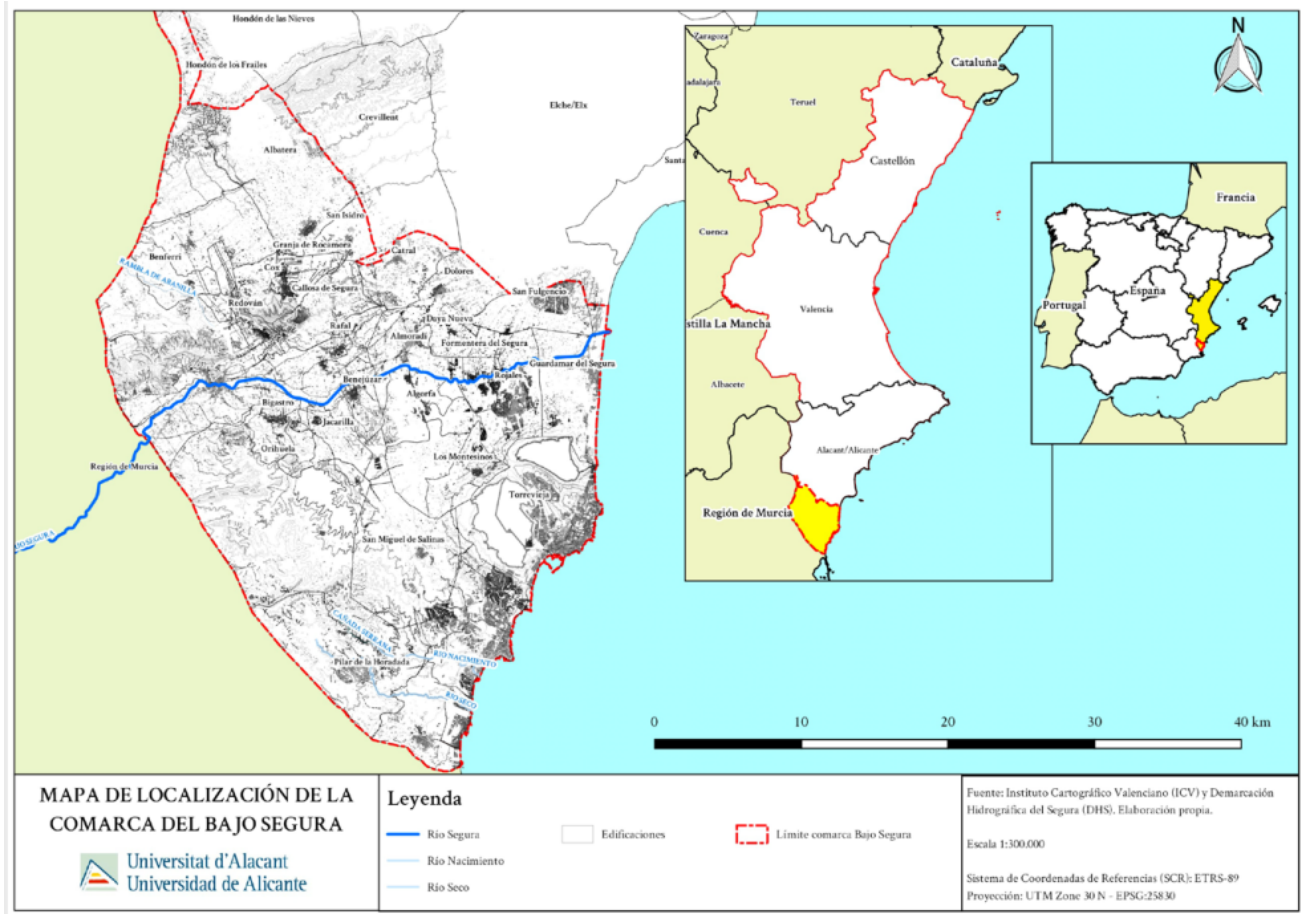

Fuente: Elaboración propia. 
La primera actividad (sesiones 1 y 2 ) tiene el objetivo de que el alumnado realice un diagnóstico de esta región atendiendo las condiciones físico-ecológicas, ordenación territorial y demográficas, al igual que conocer cuáles son las áreas de riesgo con la consulta del visor del PATRICOVA. En cuanto a la segunda actividad (sesiones 3 y 4), esta tiene la finalidad de que los discentes analicen las causas y consecuencias del episodio de lluvias torrenciales del 12 y 13 de septiembre de 2019 y comprueben cuáles son las áreas urbanas actuales que se encuentran en zona de riesgo.

Tabla 3. Propuesta curricular para tratar los riesgos de inundación en la Geografía de $2^{\circ}$ de Bachillerato. Caso de estudio de la comarca de la Vega Baja (Alicante)

\begin{tabular}{|c|c|c|}
\hline Contenidos & Criterios de evaluación & Estándares de aprendizaje \\
\hline $\begin{array}{l}\text {-Características territoriales del } \\
\text { área de estudio atendiendo a las } \\
\text { condiciones climáticas, cursos } \\
\text { fluviales, relieve, etc. } \\
\text {-Análisis del histórico de episodios } \\
\text { de lluvias de fuerte intensidad } \\
\text { horaria y sus consecuencias. } \\
\text {-Características de la ordenación } \\
\text { territorial y usos urbanos. } \\
\text {-Población y vivienda. } \\
\text {-Uso del visor cartográfico del } \\
\text { PATRICOVA y análisis de las } \\
\text { áreas de riesgo. prensa para } \\
\text {-Análisis de la de des } \\
\text { comprobar los daños económicos, } \\
\text { materiales y humanos. } \\
\text {-Causas y consecuencias de las } \\
\text { inundaciones del 12-13 de } \\
\text { septiembre de } 2019 \text {. } \\
\text {-Principales consecuencias del } \\
\text { cambio climático y escenarios } \\
\text { futuros. }\end{array}$ & $\begin{array}{l}\text {-Diagnosticar las características } \\
\text { territoriales y físico-ecológicas } \\
\text { principales } \\
\text { climáticas, cursos fluviales, } \\
\text { relieve). } \\
\text {-Analizar los episodios históricos } \\
\text { de lluvias de fuerte intensidad } \\
\text { horaria que provocaron graves } \\
\text { problemas de inundación. } \\
\text {-Reconocer la configuración } \\
\text { territorial atendiendo al proceso de } \\
\text { ordenación y usos urbanos. } \\
\text {-Saber utilizar el visor cartográfico } \\
\text { del PATRICOVA y reconocer las } \\
\text { principales áreas afectadas por el } \\
\text { riesgo de inundación. } \\
\text {-Analizar noticias de prensa para } \\
\text { su posterior interpretación e } \\
\text { identificación de las consecuencias } \\
\text { de estos fenómenos. } \\
\text {-Reconocer las causas y } \\
\text { consecuencias de las inundaciones } \\
\text { del 12-13 de septiembre de } 2019 . \\
\text {-Comprender los efectos } \\
\text { principales derivados del cambio } \\
\text { climático y los escenarios futuros. }\end{array}$ & $\begin{array}{l}\text {-Diagnostica las principales } \\
\text { características territoriales y físico- } \\
\text { ecológicas } \\
\text { climáticas, condiciones } \\
\text { relieve). } \\
\text {-Reconoce los principales } \\
\text { episodios históricos de lluvias de } \\
\text { fuerte intensidad horaria que } \\
\text { provocaron graves problemas de } \\
\text { inundación. } \\
\text {-Entiende como se ha producido la } \\
\text { configuración territorial } \\
\text { atendiendo al proceso de } \\
\text { ordenación y usos urbanos. } \\
\text {-Maneja el visor cartográfico del } \\
\text { PATRICOVA y reconoce las } \\
\text { principales áreas afectadas por el } \\
\text { riesgo de inundación. } \\
\text {-Analiza las noticias de prensa e } \\
\text { identifica las consecuencias de } \\
\text { estos fenómenos. } \\
\text {-Reconoce las causas } \\
\text { consecuencias de las inundaciones } \\
\text { del 12-13 de septiembre de } 2019 \text {. } \\
\text {-Comprende los } \\
\text { principales causados por el cambio } \\
\text { climático y escenarios futuros. }\end{array}$ \\
\hline
\end{tabular}

Fuente: Elaboración propia.

Para completar estas sesiones, el docente debe preparar y facilitar un texto explicativo con los contenidos objeto de estudio. A modo de ejemplo, a continuación, 
en el punto 3.1 se propone diferente información descriptiva que ayudará al alumnado a comprender e interpretar el territorio de análisis.

\subsection{La Vega Baja del Segura. Un territorio de riesgo}

\subsubsection{Características climáticas. Un territorio de extremos}

La comarca Vega Baja del Segura forma parte del territorio más meridional de la provincia de Alicante, en lo que algunas divisiones comarcales han denominado, en sentido amplio, el Bajo Segura. Está integrada en la región climática del sureste peninsular siendo una de las de menor precipitación de la Península Ibérica y de Europa (ver Figura 3). El denominador común de sus observatorios es la escasez de precipitaciones, con duras y prolongadas sequías, sin perjuicio de esporádicos diluvios de elevada, y hasta excepcional, intensidad horaria (Gil y Olcina, 2017). Ejemplo de ello fue el episodio del 12-13 de septiembre de 2019 con la gota fría o Depresión Aislada en Niveles Altos (DANA), alcanzando intensidades y volúmenes de precipitación muy elevadas, característica de las lluvias torrenciales del mediterráneo, llegando a superar los valores medios de precipitación anual. Por ejemplo, en el observatorio de Orihuela se registraron $500 \mathrm{~mm}$., en el conjunto del episodio de lluvias (12-13 de septiembre) con intensidades horarias de $200 \mathrm{~mm}$., en una hora (12 de septiembre).

Figura 3. Precipitación media anual en el territorio ibérico español y en Baleares (1980-2010)

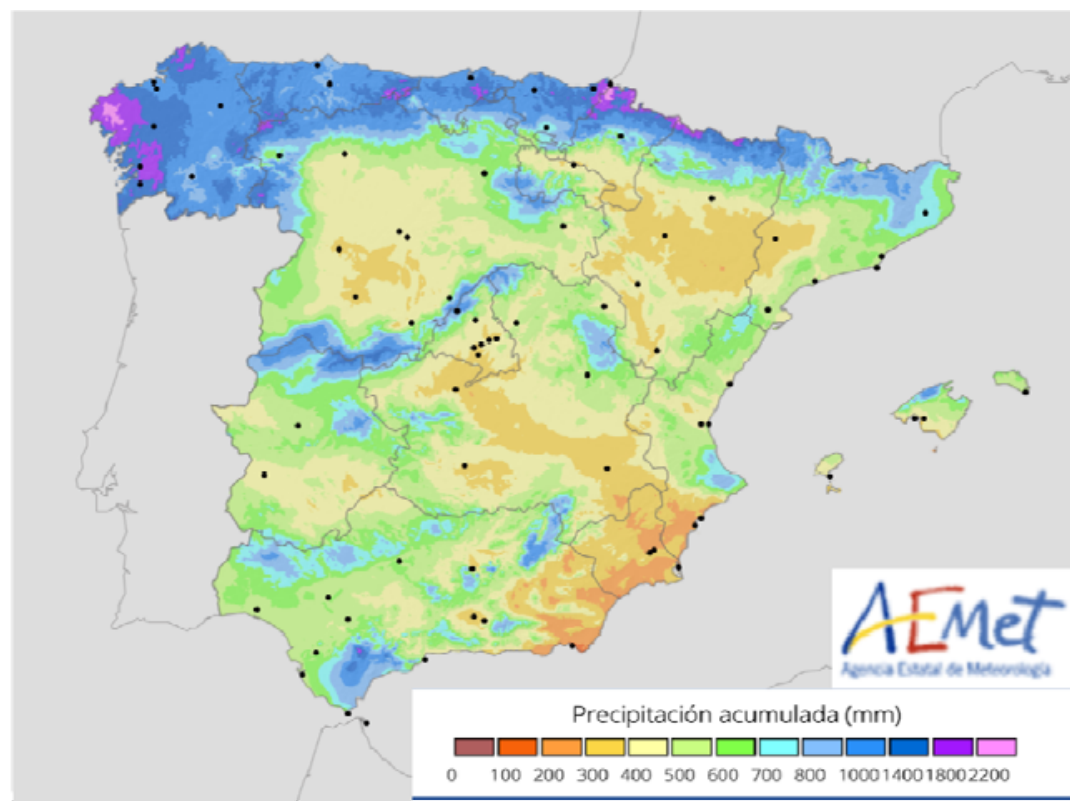

Fuente: AEMET (2021). 
El periodo anual de menor precipitación es el intervalo estival que se extiende a algunos meses de la primavera y otoño, de manera que llega a tener una larga duración (5-6 meses) e intensidad. Las precipitaciones medias anuales llegan a valores inferiores de $300 \mathrm{~mm}$ (Orihuela, $317 \mathrm{~mm}$; Guardamar del Segura, $287 \mathrm{~mm}$; Torrevieja, $271 \mathrm{~mm}$ ). Los meses más favorables para las lluvias son los meses de otoño y primavera, con picos acusados (Gil y Olcina, 2017). El número de días de lluvia al año es escaso y oscila entre 30-50 (Canales et al., 1995). En cuanto a las temperaturas, la media mensual más fría no desciende de $\operatorname{los} 8^{\circ} \mathrm{C}$, presentando una amplitud térmica superior a $18^{\circ} \mathrm{C}$ y una media anual inferior a $16^{\circ} \mathrm{C}$ (Gil y Olcina, 2017). Las temperaturas medias anuales se sitúan en el entorno de los $18{ }^{\circ} \mathrm{C}$, sobre todo por las temperaturas suaves invernales (Olcina y Moltó, 2019). En resumen, la comarca de la Vega Baja del Segura se caracteriza por presentar temperaturas suaves, sin grandes alteraciones térmicas salvo cuando acontecen eventos de temperatura excepcional (olas de frío y calor), con unas precipitaciones medias anuales muy escasas y con una acusada irregularidad interanual e intraanual, así como una concentración temporal (horaria) muy destacada, con génesis de episodios de lluvia torrencial de forma frecuente, con veranos muy secos y desarrollo de eventos de sequía (Gil y Olcina, 2017).

\subsubsection{Antropización del territorio basado en el turismo residencial y la agricultura de regadío}

La comarca de la Vega Baja del Segura es un territorio con riesgo natural elevado, con ocupación antrópica histórica, pero profundamente alterado desde la segunda mitad del pasado siglo XX con la implantación de usos del suelo en áreas que presentan comportamiento natural extremo.

En este espacio geográfico convergen: 1) una agricultura tradicional en torno al caucel del río Segura, implantada desde época musulmana; 2) una agricultura moderna, tecnificada, que se ha extendido desde los años setenta del siglo XX gracias a la llegada de aguas del Acueducto Tajo-Segura (ATS); y 3) una actividad turística muy extendida en la franja litoral, que ha apostado por el modelo de residencialismo, distorsionando la estructura urbana tradicional de los núcleos de población de la comarca (Figura 4).

Y ello, caracterizado por la existencia de numerosas infraestructuras viarias de conexión interna y externa (carreteras nacionales, autovías), repercutiendo en un valor elevado de vulnerabilidad ante el peligro, asimismo muy alto, de inundaciones que se registra en este territorio. Algunos datos de urbanización en algunas localidades ponen de manifiesto como este sector de la costa alicantina ha sido uno en los que más se ha incrementado el suelo urbano para usos turísticos y residenciales. 
Figura 4. Urbanizaciones del término municipal de San Fulgencio (Alicante)

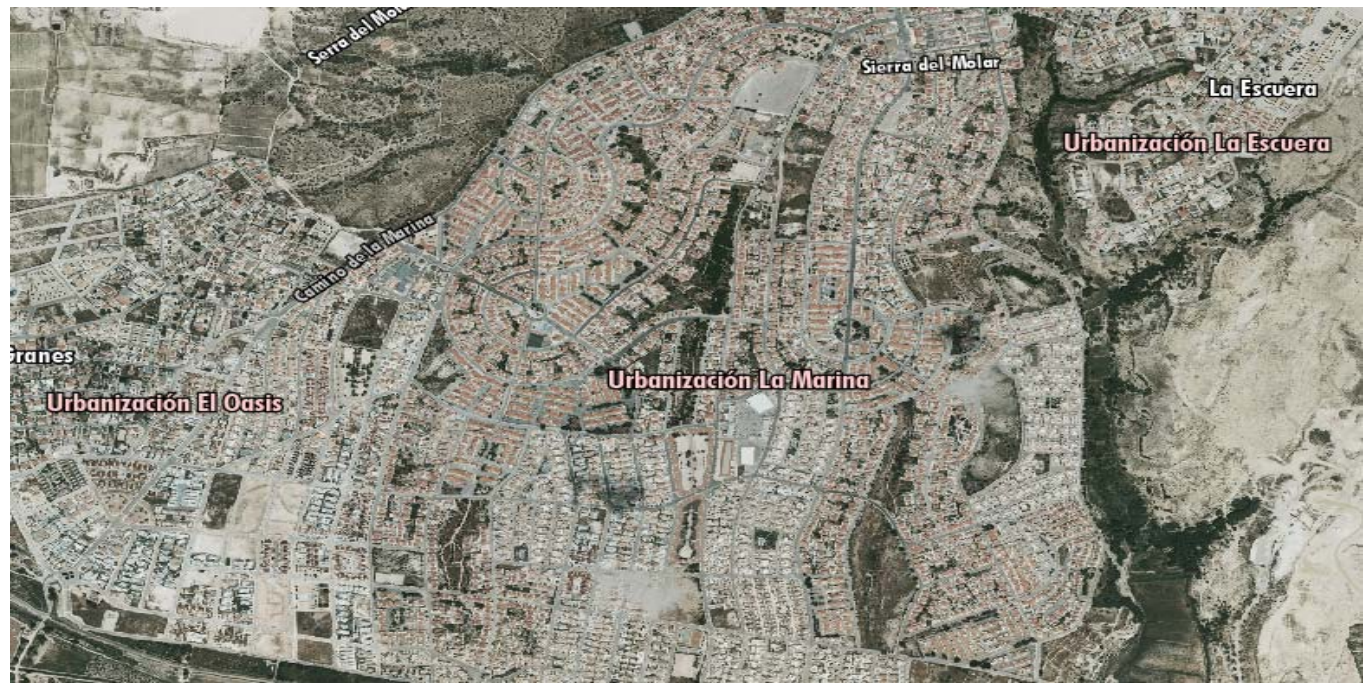

Fuente: ICV (2021).

Por ejemplo, en localidades como Orihuela o Torrevieja, el suelo ocupado por urbanizaciones (chalés, viviendas adosadas, principalmente) representan el $67,2 \%$ en Torrevieja (36,6\% los adosados y el 30,6\% los chalés) mientras que en Orihuela esta superficie residencial representa el $84,7 \%$ (10,8\% los adosados y el 73,9\% los chalés) (Morote, 2015).

\subsubsection{El río Segura. Un curso fluvial de comportamiento extremo}

El río Segura en sus tramos medio y bajo tiene un comportamiento típicamente mediterráneo, con caudal medio poco abundante (Figura 5) y comportamiento interanual muy irregular y crecidas importantes con ocasión de lluvias torrenciales. Este mismo comportamiento, aunque con un caudal mucho más escaso e incluso nulo durante meses o años, corresponde a las ramblas y barrancos del tramo bajo de Segura, ya en la provincia de Alicante (rambla de Abanilla, rambla del Derramador, como cursos más destacados), que experimentan crecidas súbitas con gran capacidad de arrastre en caso de precipitaciones intensas. La Vega Baja del Segura, desde el punto de vista hidrológico, se inunda bien por las propias crecidas del río Segura, bien por avenidas procedentes del río Guadalentín, que coinciden con crecidas del propio rio Segura, o bien por la participación más localizada de las crecidas de la rambla de Abanilla o del Derramador, que aportan caudales complementarios generalmente a la propia crecida del Segura.

La Vega Baja del Segura ha sufrido numerosos episodios de inundación provocados por la reactivación de los barrancos y ramblas, que descienden de los relieves más próximos (Sierra de Orihuela y Callosa), y de los continuos 
desbordamientos del río Segura. El desbordamiento de mayores consecuencias socioeconómicas y territoriales de la historia contemporánea tuvo lugar el 14-15 de octubre de 1879, la conocida "riada de Santa Teresa", que causó más de 1.000 víctimas mortales (300 en Orihuela) y destrucción de 5.762 viviendas (Luján y GarcíaMartínez, 2019).

Figura 6. Río Segura a su paso por la ciudad de Orihuela (capital de la comarca de la Vega Baja)

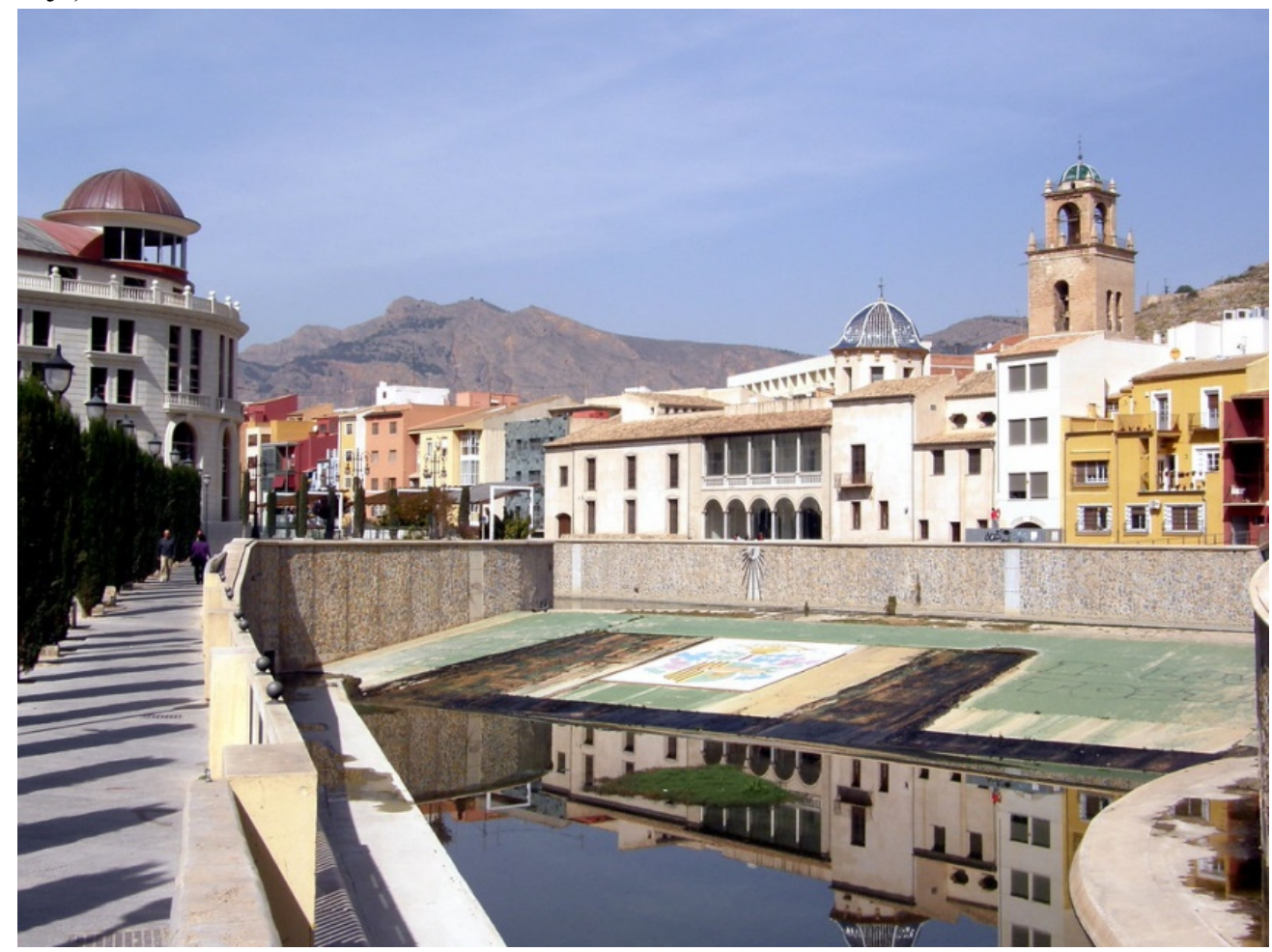

(*) Nota: cauce y caudal del río Segura a su paso por la ciudad de Orihuela en condiciones de normalidad.

Fotografía de los autores.

Desde el final de la Guerra Civil, la comarca ha conocido inundaciones muy destacadas que han dado lugar a propuestas diversas, hasta el desarrollo de la riada de noviembre de 1987 que motivó la aprobación por vía de urgencia del Plan de Defensa de Avenidas de la Cuenca del Segura (1987). Esta fecha establece el inicio cronológico del presente apartado dedicado a analizar los episodios de inundación ocurridos en los últimos treinta años en la Vega Baja del Segura. En la Tabla 4 se incluye un resumen del impacto de esas inundaciones tanto a nivel social como económico. 
Tabla 4. Inundaciones importantes en la Vega Baja del Segura (1946-2019)

\begin{tabular}{|c|c|c|c|c|c|c|c|}
\hline $\begin{array}{c}\text { Fecha } \\
\text { (Días/m } \\
\text { es) }\end{array}$ & Año & $\begin{array}{c}\text { Precipitación } \\
\text { Orihuela }\left(1 / \mathbf{m}^{2}\right)\end{array}$ & $\begin{array}{l}\text { Aforo Caudal } \\
\qquad\left(\mathrm{m}^{3} / \mathrm{s}\right)\end{array}$ & Inundación & $\begin{array}{l}\text { Pérdidas } \\
\text { humanas }\end{array}$ & $\begin{array}{c}\text { Pérdidas } \\
\text { económicas }\end{array}$ & $\begin{array}{c}\text { Superficie } \\
\text { inundada } \\
\text { ha. }\end{array}$ \\
\hline $19-22 / 04$ & 1946 & 109,4 & 500 (Orihuela) & Segura y otros & 0 & $34.558 €$ & 23.600 \\
\hline $25-29 / 09$ & 1947 & 75 & 750 (Orihuela) & Segura y otros & $\begin{array}{c}14 \\
\text { (Santomera) }\end{array}$ & $300.506 €$ & 1.654 \\
\hline $19-23 / 10$ & 1948 & 49,1 & 950 (Orihuela) & Segura y otros & 0 & Incalculables & 894 \\
\hline $14-18 / 02$ & 1949 & 26,2 & 700 (Orihuela) & Segura y otros & 0 & + Año 1946 & 1.000 \\
\hline $22-24 / 04$ & 1951 & 52 & - & Segura & 0 & - & - \\
\hline $11-16 / 10$ & 1957 & - & 155 (Rojales) & Segura & 0 & - & - \\
\hline 14-19/09 & 1962 & 19,5 & - & Segura y Abanilla & 0 & $240.405 €$ & 2.236 \\
\hline $22-23 / 12$ & 1964 & 32 & - & Segura y otros & 0 & $+780 €$ & +950 \\
\hline $09-10 / 12$ & 1965 & 126 & 200 (Orihuela) & $\begin{array}{c}\text { Abanilla, } \\
\text { Derramador y } \\
\text { Segura }\end{array}$ & 0 & $540.911 €$ & 2.012 \\
\hline $11-15 / 09$ & 1966 & 36 & - & Abanilla & 0 & $901.518 €$ & 1.788 \\
\hline $10-12 / 10$ & 1966 & 55 & 300 (Rojales) & $\begin{array}{c}\text { Abanilla, } \\
\text { Derramador y } \\
\text { Segura }\end{array}$ & 0 & - & - \\
\hline $14-15 / 02$ & 1967 & 55 & - & $\begin{array}{c}\text { Derramador y } \\
\text { Abanilla }\end{array}$ & 0 & - & 134 \\
\hline $17-19 / 04$ & 1967 & 36 & - & Abanilla & 0 & $90.151 €$ & 1.118 \\
\hline $03-05 / 05$ & 1967 & - & - & Abanilla & 0 & - & - \\
\hline $01-03 / 02$ & 1968 & 52 & - & $\begin{array}{l}\text { Abanilla y } \\
\text { Derramador }\end{array}$ & 0 & - & - \\
\hline $11-12 / 06$ & 1968 & 14 & - & Abanilla & 0 & - & - \\
\hline $23-25 / 10$ & 1971 & 27,5 & - & $\begin{array}{c}\text { Derramador y } \\
\text { Abanilla }\end{array}$ & 0 & $\begin{array}{c}3.666 .174 € \\
\text { (prov. } \\
\text { Alicante) }\end{array}$ & 2.955 \\
\hline $17-19 / 10$ & 1972 & 132 & 350 (Orihuela) & Segura y otros & 0 & $436.084 €$ & 2.873 \\
\hline $17-19 / 10$ & 1973 & 19 & 354 (Orihuela) & Segura y otros & $\begin{array}{c}200 \text { (Murcia, } \\
\text { Granada, } \\
\text { Almería) }\end{array}$ & $150.253 €$ & 2.727 \\
\hline $19-20 / 10$ & 1982 & 67,8 & 115(Orihuela) & Segura y otros & 1 (Rojales) & - & - \\
\hline $01-04 / 10$ & 1986 & 37,6 & 380 (Orihuela) & Segura y otros & $\begin{array}{c}1 \text { (La Zénia) } \\
1 \text { (Cabo Roig) } \\
3 \text { (Murcia) }\end{array}$ & $2.103 .542 €$ & - \\
\hline $13-14 / 10$ & 1986 & 40 & 439 (Orihuela) & Segura y otros & 1 (Orihuela) & $+2.104 .107 €$ & 700 \\
\hline
\end{tabular}




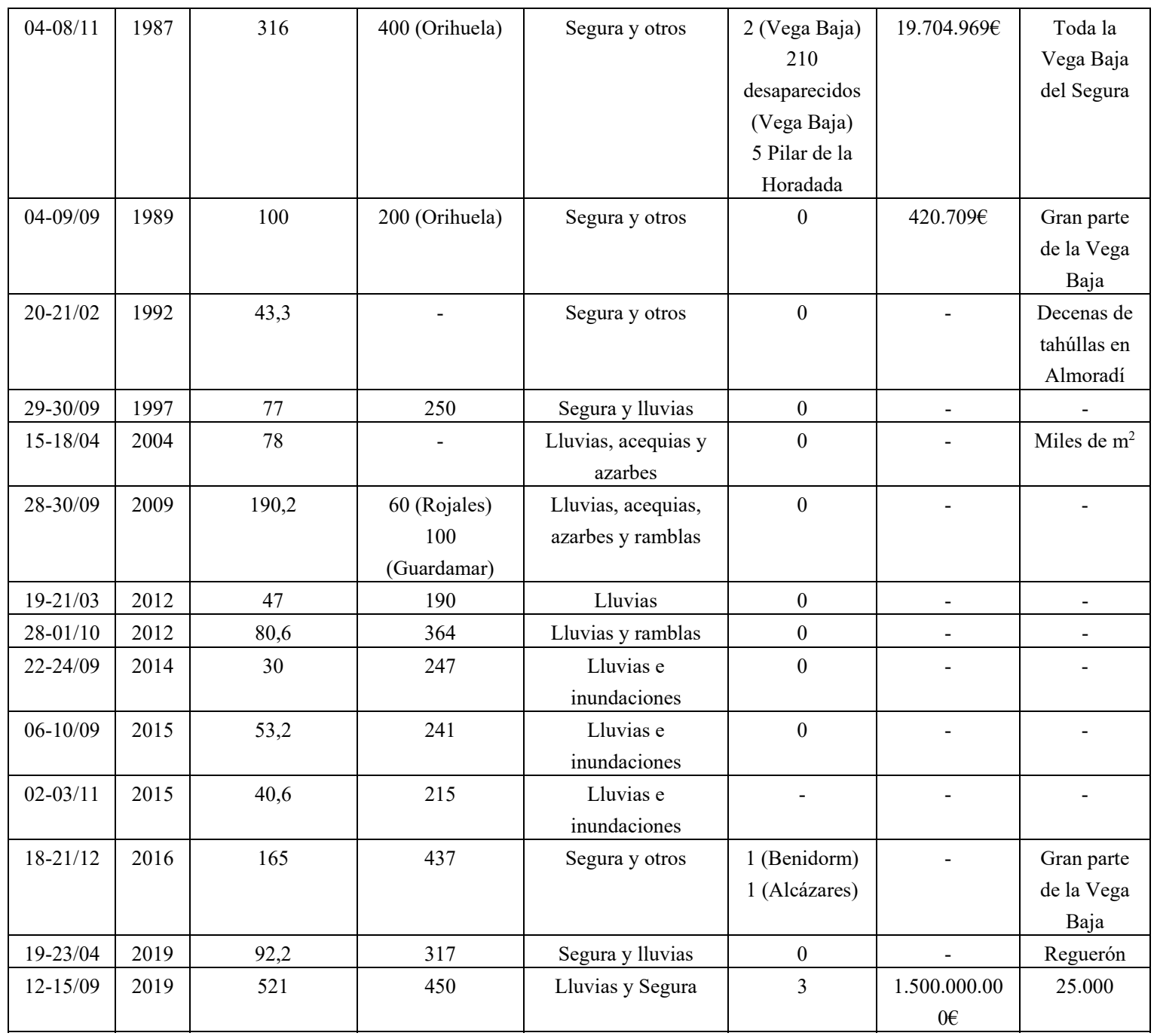

(*) Nota: Se incluyen los caudales máximos registrados en aforo que han circulado por el río Segura en momentos de crecida y, en ocasiones, desbordamiento.

Fuente: Diario Información (1946-2019). Elaboración propia. 


\subsubsection{El episodio de lluvias torrenciales y graves inundaciones del 12-13 de septiembre de 2019. Un fenómeno reiterado en la comarca}

La formación de la situación de gota fría o DANA que originó la inundación de la Vega Baja del Segura a mediados de septiembre de 2019 (días 12 y 13), se fraguó unos días antes en la escena sinóptica. El lunes 9 de septiembre una masa de aire polar marítimo descendió en la vertical en forma de vaguada con eje norte-sur afectando a la Península Ibérica. El martes 10 se produce el desgajamiento y la consolidación de una gota fría en el interior de dicha vaguada. El miércoles 11, el núcleo de esta gota fría se localizó en la alta troposfera, entre el mar de Alborán y el mar de Argel, situando la zona de mayor inestabilidad sobre el este y sureste peninsular. Este hecho favoreció el desarrollo de un proceso ciclogenético mediterráneo con formación de una baja propia, in situ, en el mar de Argel. Por tanto, bolsa de aire frío en las capas altas de la atmósfera (gota fría o DANA) y desarrollo ciclogenético de Argel en las capas bajas de la troposfera, fueron las condiciones idóneas para la formación de potentes núcleos de tormenta que generaron precipitaciones de fuerte intensidad horaria entre la provincia de Castellón y la Región de Murcia (Figura 7). Además, cabe indicar que la lluvia asociada a este episodio se extendió entre los días 11 y 15 de septiembre.

Figura 7. Situación atmosférica del día 13 de septiembre de 2019
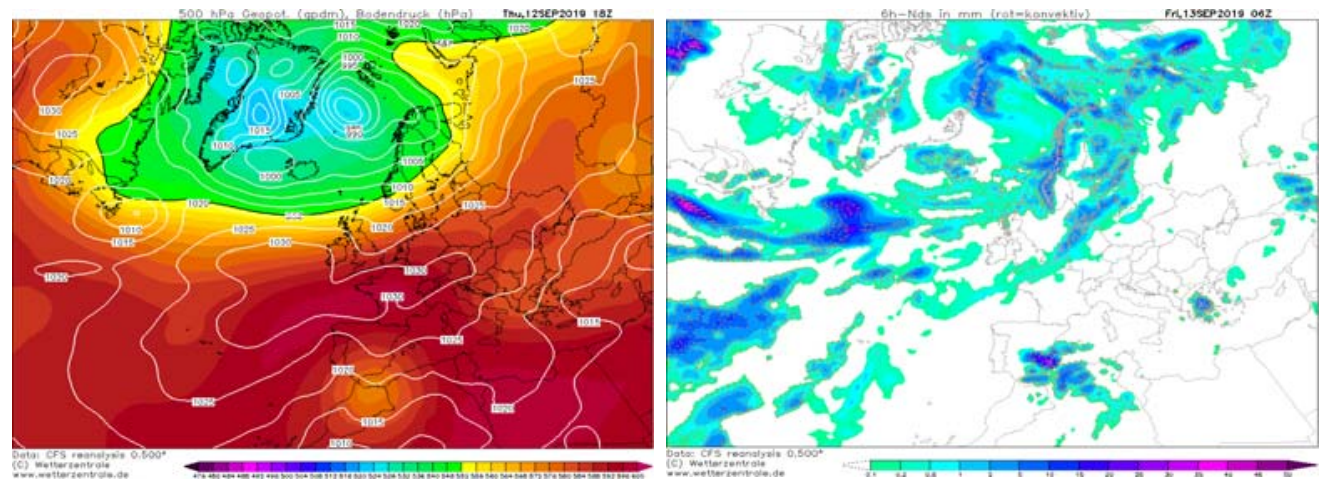

Fuente: Wetterzentrale (2021).

A lo largo de la jornada del 12 de septiembre, las tormentas intensas comenzaron en el norte de la provincia de Alicante y sur de Valencia, generando inundaciones importantes. Con el paso de las horas de la jornada del 12 de septiembre, las lluvias torrenciales, derivadas de la formación de un enérgico sistema convectivo, se concentraron en el tramo bajo de la cuenca del Segura y litoral murciano del Mar Menor y Campo de Cartagena. Para el caso de la provincia de Alicante, en Orihuela, se registraron $250 \mathrm{l} / \mathrm{m}^{2}$ en tan sólo 2 horas. Situación similar que aconteció en el resto de la Vega Baja en diferentes localidades. 
En el sur de la provincia de Alicante, este episodio ha sido el mayor temporal desde el ocurrido a principios de noviembre de 1987, cuando se registró una precipitación de $317 \mathrm{~mm} / 24 \mathrm{~h}$. en Orihuela, causando 7 víctimas mortales en la comarca. En el evento de 2019, el área próxima a las Sierras de Orihuela y Callosa fue la que más cantidad de precipitación recogió entre el 11 y 15 de septiembre, con el dato destacado de la mayor intensidad horaria de las lluvias registrada el día 12 . Este hecho provocó la incapacidad del suelo para absolver toda el agua precipitada, lo que originó la formación de escorrentía superficial en barrancos y ramblas. Y, por supuesto, favoreció la crecida del caudal circulante del propio río Segura, al tiempo que se produjo un aumento del agua de todo el sistema de acequias y azarbes de la Vega Baja. Las lluvias del día 12 provocan anegaciones en infraestructuras (carreteras, vías de tren, túneles, etc.), en los campos de cultivo y muchos municipios que forman la Vega Baja (Figura 8).

Figura 8. Vista de la inundación de septiembre de 2019 (comarca de la Vega Baja)

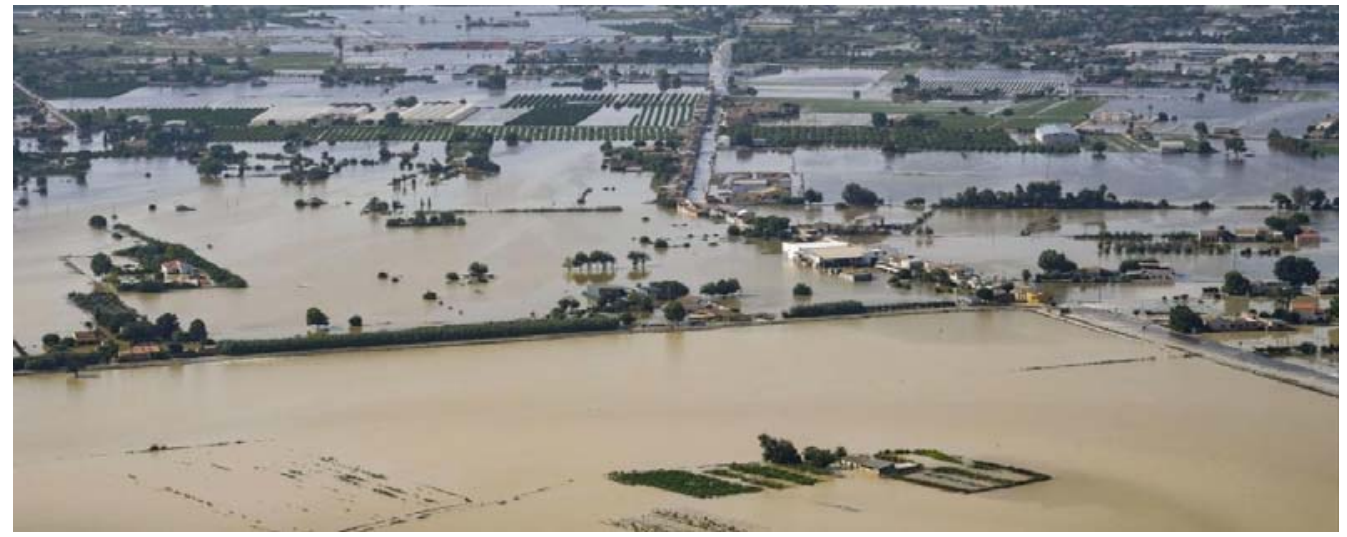

Fuente: Generalitat Valenciana (2020).

Más de 600 personas fueron rescatadas y miles de vecinos de la comarca tuvieron que abandonar sus casas tras desbordarse el Segura. Por tanto, la Vega Baja se inundó, tanto por las trombas de lluvias como por el desbordamiento del río Segura, al romperse el encauzamiento en Almoradí, Benejúzar y Algorfa, anegando otros tantos núcleos urbanos como las Dayas y Dolores, así como enormes extensiones de huerta y urbanizaciones diseminadas que quedaron completamente aisladas. La AP-7 quedó completamente colapsada y cortada en puntos como el túnel de Pilar de la Horadada o el tramo entre Albatera y Granja de Rocamora. Pueblos como Almoradí y Benferri se quedaron sin servicio de agua potable. Algunos titulares que recogió la prensa regional durante esos días fueron "La gota fría más violenta en 140 años se cobra otra vida y el Segura no cede" (Diario Las Provincias, 15.09.2020), comparando este episodio con la famosa "Riada de Santa Teresa" de octubre de 1879. Los muy cuantiosos efectos económicos de este episodio llevaron a la declaración de la comarca como zona catastrófica por parte del gobierno. 


\subsection{Propuesta de actividades para la enseñanza del riesgo de inundación en la comarca de la Vega Baja del Segura (Comunidad Valenciana)}

\subsubsection{Actividad 1. Diagnóstico territorial del área de estudio. Una región donde el riesgo de inundación constituye un rasgo estructural}

En la primera sesión de la Actividad 1 se proponen 3 ejercicios (ver Tabla 5). En el primero, a partir del texto y la cartografía de referencia proporcionada (mapa topográfico nacional disponible en el visor del ICV) y la explicación proporcionada por el docente, el alumnado debe reconocer y explicar el clima y el funcionamiento del principal curso fluvial que articula este espacio (río Segura), sus principales tributarios y principales características (régimen, fluvial, usos del agua, clima, etc.). En cuanto al ejercicio 2, este tiene la finalidad de que los discentes analicen las consecuencias en el territorio de las principales riadas históricas acaecidas en el área de estudio. En el tercer ejercicio, el/la alumno/a, a partir del visor del PATRICOVA, debe reconocer los municipios que están afectados por el riesgo de inundación. Para esta propuesta se prestará especial atención a las áreas afectadas por el río Segura (Figura 9). Además, en este ejercicio, los dicentes deben elaborar una tabla (ficha que facilita el docente) y registrar todos los municipios afectados e indicar los tipos de niveles de riesgo que le afectan (ver Tabla 6).

Tabla 5. Ejercicios propuestos para la Actividad 1 (sesiones 1 y 2)

\begin{tabular}{|l|}
\hline Sesión 1 \\
\hline -Ejercicio 1. Identifica y describe el clima y los principales cursos fluviales del área de \\
estudio. \\
-Ejercicio 2. Analiza y describe las consecuencias acaecidas en el área de estudio \\
coincidiendo con las principales riadas históricas (s. XX-XXI). \\
-Ejercicio 3. Utiliza el visor SIG del PATRICOVA iqué municipios están afectados por el \\
riesgo de inundación? A partir de la ficha facilitada por el docente, registra todos los \\
municipios de la comarca afectados por el riesgo de inundación del río Segura atendiendo a \\
los diferentes niveles de riesgo asignados por el PATRICOVA.
\end{tabular}

\section{Sesión 2}

-Ejercicio 4. Consulta el Instituto Nacional de Estadística (INE) (https://www.ine.es/). A partir de los municipios identificados en el ejercicio 3, registra el número de habitantes censados en estas localidades. A continuación, desagrégalos entre españoles y extranjeros ¿crees que esta diferenciación puede tener alguna incidencia en el riesgo?

-Ejercicio 5. Consulta el Instituto Nacional de Estadística (INE) (https://www.ine.es/). Registra el número de hogares censados (último censo de 2011) y desagrega las viviendas por tipología (principal, secundaria y vacía) de los municipios identificados. ¿Qué municipios tienen un mayor número de viviendas secundarias? ¿con qué se relacionan?

Fuente: Elaboración propia. 
Figura 9. Áreas de riesgo de inundación en la comarca de la Vega Baja (Alicante)

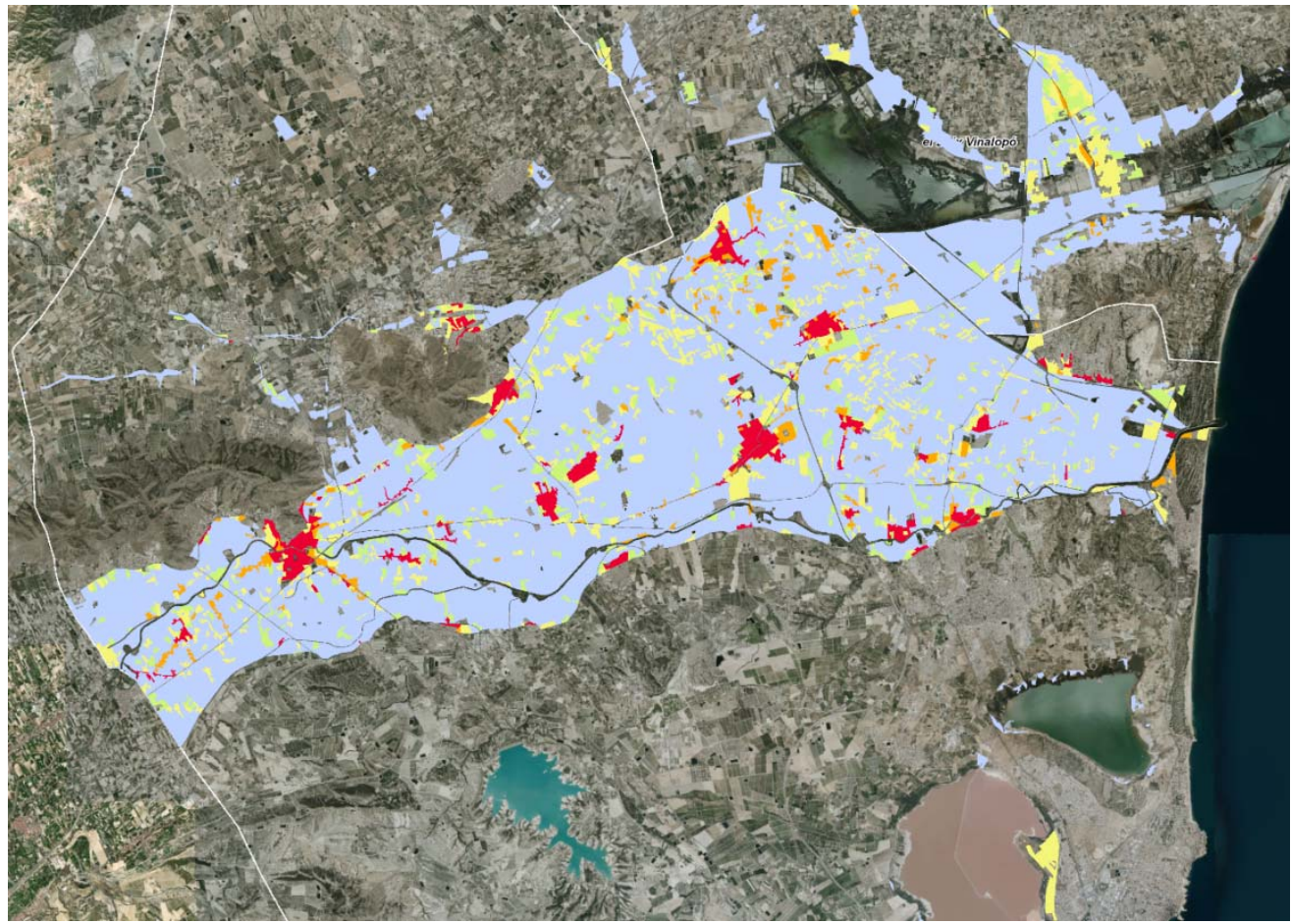

Fuente: PATRICOVA (2021). Nota: Niveles de riesgo: rojo ("muy alto"), naranja ("alto"), amarillo ("medio"), verde ("bajo"), azul ("muy bajo"). Los colores rojos coinciden con los principales núcleos de población.

Tabla 6. Propuesta de ficha que deben rellenar los discentes para la Actividad 1.

\begin{tabular}{|l|l|}
\hline Municipio & \\
\hline Niveles de riesgo que le afectan & \\
\hline $\mathbf{N}^{\circ}$ habitantes & \\
\hline $\mathbf{N}^{0} \mathbf{y} \%$ españoles & \\
\hline $\mathbf{N}^{0} \mathbf{y} \%$ extranjeros & \\
\hline $\mathbf{N}^{\circ}$ total de viviendas & \\
\hline $\mathbf{N}^{0} \mathbf{y} \%$ viviendas principales & \\
\hline $\mathbf{N}^{0} \mathbf{y} \%$ viviendas secundarias & \\
\hline $\mathbf{N}^{0} \mathbf{y} \%$ viviendas vacías & \\
\hline
\end{tabular}

Fuente: Elaboración propia.

En la segunda sesión, y con la ficha de municipios del día anterior, el alumnado debe buscar en el Instituto Nacional de Estadística (https://www.ine.es/), según los municipios identificados que tienen riesgo de inundación (río Segura): 1) el total de habitantes censados, diferenciar entre españoles y extranjeros (número y porcentaje) 
(ejercicio 4); y 2) total de viviendas, y diferenciar entre tipologías (principal, secundaria y vacía) (ejercicio 5). En cuanto al aspecto demográfico, interesa reconocer el porcentaje de población extranjera respecto al total para ver si el/la alumno/a describe alguna opinión o análisis sobre la posible incidencia en el riesgo de esta cohorte poblacional debido al desconocimiento del territorio por parte de este contingente que reside en esta parte del sur de la provincia de Alicante. En cuanto a las viviendas, se valorará si los discentes saben interpretar y relacionar las viviendas secundarias con urbanizaciones y con la población extranjera. También, de este análisis, se tendrán en cuenta las descripciones de si la población española conoce el territorio donde reside. Se trata, por tanto, de analizar si el alumnado identifica los prejuicios sobre la población extranjera en comparación con la española atendiendo a si conocen o no su territorio más próximo.

\subsubsection{Actividad 2. Análisis del episodio del 12-13 de septiembre de 2019. Causas y consecuencias}

En cuanto en la segunda actividad, y concretamente la sesión 3, esta tiene el objetivo de que el alumnado identifique las principales causas que provocaron las inundaciones del episodio del 12-13 de septiembre de 2019 teniendo en cuenta tanto las causas climáticas como humanas (ejercicio 1) (Tabla 7). Respecto al ejercicio 2 se plantea que los discentes describan las consecuencias acaecidas tras este episodio durante los días siguientes. Para responder a estas preguntas, el alumnado debe tener en cuenta tanto el texto explicativo proporcionado como la explicación del docente. Además, en cuanto a las consecuencias se propone que busquen información sobre los efectos en la prensa digital durante los días siguientes del episodio.

Tabla 7. Ejercicios propuestos para la Actividad 2 (sesiones 3 y 4 )

\begin{tabular}{|l|}
\hline Sesión 3 \\
\hline -Ejercicio 1. ¿Cuáles fueron las principales causas de las inundaciones del episodio del 12- \\
13 de septiembre de 2019 ? \\
-Ejercicio 2. ¿Cuáles fueron las principales consecuencias de las inundaciones del episodio \\
del 12-13 de septiembre de 2019 ? Apóyate también con la consulta de la prensa digital de \\
los días posteriores. \\
\hline Sesión 4 \\
\hline -Ejercicio 3. Utiliza el visor SIG del PATRICOVA (https://visor.gva.es/visor/). Carga las \\
capas de usos del suelo y las capas de mayor riesgo (niveles 1 y 2). ¿Con qué coinciden \\
estas capas de riesgo? ¿hay zonas urbanas dentro de estas capas de información? \\
-Ejercicio 4. Valorar el posible incremento futuro del riesgo de inundación en la comarca \\
teniendo en cuenta el contexto actual de cambio climático a partir de la consulta del visor \\
Adaptecca (www.adaptecca.es) y los escenarios futuros de precipitación de la provincia de \\
Alicante a partir de la AEMET \\
(http://www.aemet.es/es/serviciosclimaticos/cambio_climat/result_graficos). \\
\hline
\end{tabular}

Fuente: Elaboración propia. 
En la cuarta y última sesión, se propone que el alumnado, nuevamente, utilice el visor SIG del PATRICOVA. Deben consultar la cartografía de riesgo, concretamente los principales niveles ("muy alto" y "alto") y la capa de usos del suelo (ejercicio 3). El objetivo, por tanto, es que los discentes comprueben la situación actual de la comarca de la Vega Baja (entorno del río Segura) donde una importante superficie de suelo urbano se encuentra en áreas potenciales de riesgo (Figura 10). Aquí se valorará si saben vincular este solapamiento de la cartografía con los datos recopilados en la ficha (Tabla 6) y la información descrita sobre las viviendas y urbanizaciones que se suelen asociar con segundas residencias (Actividad 1).

Figura 10. Áreas de riesgo de inundación en la ciudad de Orihuela
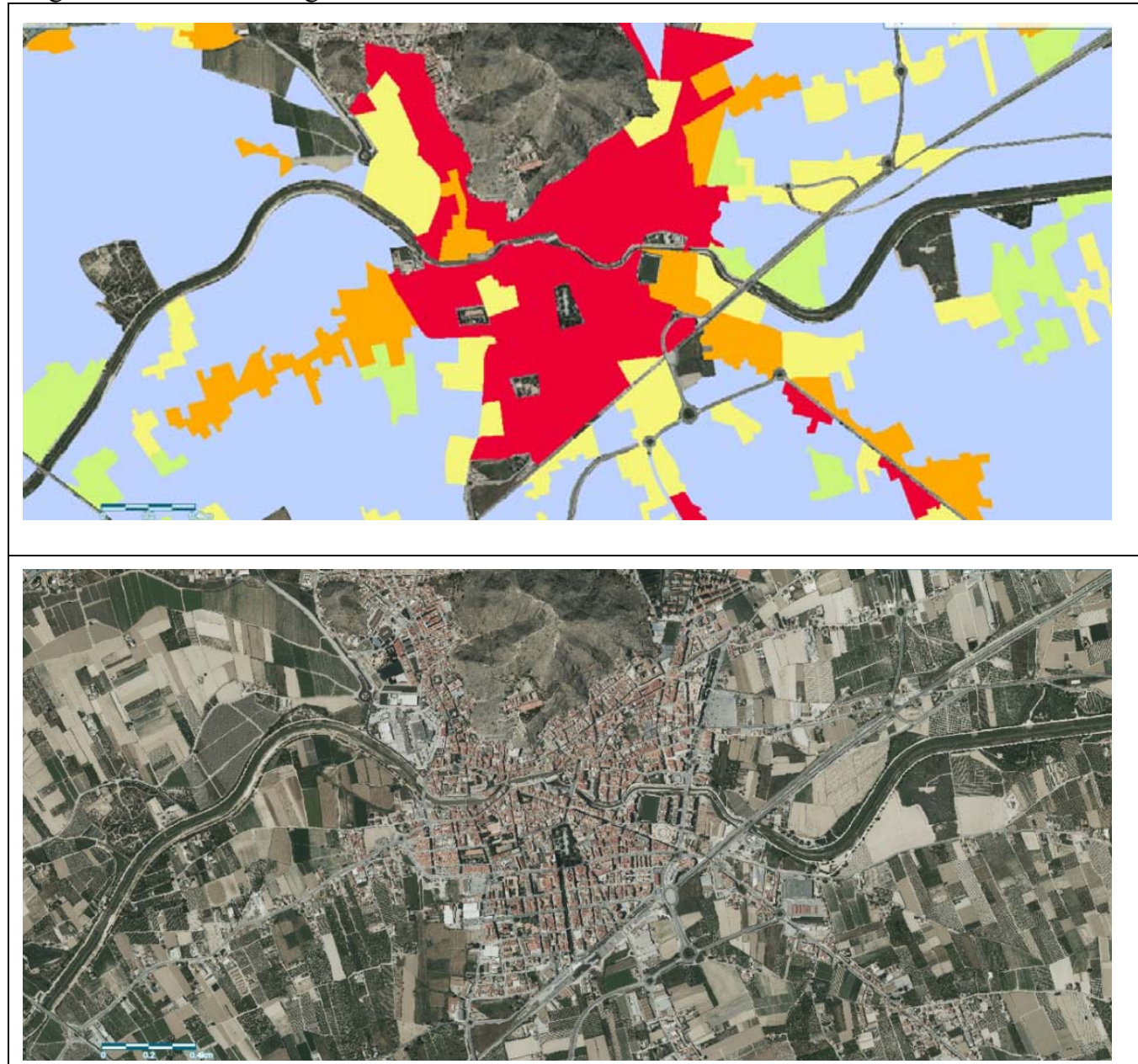

Fuente: PATRICOVA (2021). Nota: Niveles de riesgo: rojo (muy alto), naranja (alto), amarillo (medio), verde (bajo), azul (muy bajo). Los colores rojos coinciden con los principales núcleos de población. 
Respecto al ejercicio 4, el objetivo es que el alumnado valore el posible incremento futuro del riesgo de inundación en la comarca a la vista de lo que señala la modelización climática en el actual contexto de cambio climático. Para ello, y teniendo en cuenta el mapa de riesgo de inundación del PATRICOVA, se consultará la página de Adaptecca (www.adaptecca.es). Con este visor interactivo, el alumnado comprobará la evolución prevista en la variable de precipitación máxima en 24 h., para diferentes escenarios temporales (futuro próximo, medio y lejano). También se pueden consultar los escenarios futuros de precipitación en el ámbito provincial de la zona de estudio (en este caso, Alicante), elaborados por la Agencia Estatal de Meteorología (AEMET) y disponibles en su página web (http://www.aemet.es/es/serviciosclimaticos/cambio_climat/result_graficos). Con ello se completa la visión del riesgo de inundación en la comarca de la Vega Baja del Segura, de forma integral, a través de las actividades planteadas para en este trabajo.

\section{Discusión y conclusiones}

Este trabajo propone una serie de actividades que se pueden implementar en el aula para la mejor comprensión del riesgo de inundación, en el contexto de la asignatura de Geografía de $2^{\circ}$ de Bachillerato. Para ello se ha escogido un ejemplo aplicado a un área de estudio, a partir de un episodio real de inundaciones acaecido y con la consulta de un visor SIG (software libre) de la administración valenciana. Además, se intenta que el alumnado se familiarice con este tipo de herramientas (desarrollo de competencias digitales) y que aprenda a localizar e interpretar su territorio más inmediato. Asimismo, se trata de una propuesta que puede ser adaptada a otras regiones españolas e incluso en el ámbito internacional siempre que exista información de base para ello (cartografía de riesgo de inundación). De hecho, para el caso español, la posibilidad de consulta y utilización del visor del Sistema Nacional de Cartografía de Zonas Inundables (SNZCI) abre la posibilidad de la adaptación de esta propuesta a otras áreas españolas, aunque no dispongan de plan específico de escala regional.

Las actividades aquí ideadas, también deben servir para ampliar la formación de los/as docentes que imparten la asignatura de Geografía en $2^{\circ}$ de Bachillerato. En este sentido, recientemente se ha constatado que la mayoría de las clases utilizan una metodología técnica, basadas en las clases magistrales y actividades de reproducción y memorización (Morote, 2020). Por tanto, un aprendizaje poco motivador y escasamente basado en la resolución de problemas (metodología Técnica) (Rozada, 1997). Esta supone la clásica imagen de la Geografía escolar como explica Murphy (2018):

Mucha gente considera la Geografía como la simple memorización de lugares y localización de hechos, es decir, el mero saber dónde se hallan determinados lugares y conocer algunas de sus características distintivas. No es que el conocimiento de estas cosas carezca por 
completo de valor, pues permite captar conocimientos básicos de la superficie terrestre y situarse en relación con otros lugares y otras personas. Pero si toda la argumentación a favor de la Geografía se redujera al conocimiento de hechos geográficos seleccionados, se trataría en realidad de una defensa endeble, sobre todo en una época en que en treinta segundos en internet bastan para producir una respuesta a la mayoría de los interrogantes relativos a la localización de hechos y a la ubicación de lugares (p. 24).

Sin embargo, como argumenta este último autor, la Geografía es una disciplina académica y un tema de estudio que explora -y promueve el pensamiento crítico a ese respecto - cómo está organizado el mundo, los ambientes y los modelos existentes en la realidad o que los seres humanos crean en su cabeza, las interconexiones del medio físico y humano, así como la naturaleza de los distintos lugares y las diferentes regiones. En este sentido, Murphy (2018, p. 20) expresa que "la Geografía ofrece una importante ventana crítica a la diversidad natural y a la naturaleza del planeta que alberga a la humanidad".

Los ejercicios que se proponen tienen el sentido de problematizar y practicar una Geografía crítica y romper con los estereotipos del profesorado (Morote et al., 2021) y escaso rigor científico del que, en ocasiones, se nutren los principales recursos utilizados en las aulas (libro de texto) (Morote y Olcina, 2020; 2021; Olcina, 2017). Por ejemplo, estos últimos autores han analizado los contenidos sobre el cambio climático en los manuales escolares de Ciencias Sociales y Geografía (Educación Primaria, Secundaria y Bachillerato) y han demostrado cómo, de manera general, se explican contenidos poco rigurosos, descontextualizados, muy influenciados por los medios de comunicación y caracterizados por un excesivo catastrofismo.

En los libros de texto, la escasa información sobre el riesgo de inundación en los manuales escolares puede inducir, por un lado, a que los docentes no traten este tema en las aulas y, por otro, que lo traten con poco rigor. Esto mismo ha sido argumentado por Morote y Souto (2020) para el caso de las representaciones sociales de las inundaciones por parte del futuro profesorado de Educación Primaria. Estos autores han comprobado cómo sólo el 12,1\% de los/as futuros docentes (Educación Primaria) recibieron formación sobre el riesgo de inundación durante su etapa escolar. A estas conclusiones también han llegado otros investigadores (Morgan, 2012) que han demostrado que la mayoría del profesorado no se siente lo suficientemente capacitado para enseñar esta temática debido a la escasa formación recibida.

Una de las cuestiones clave que se tiene que tener en cuenta cuando se explica el riesgo de inundación (como aquí se ha hecho) es contemplar el factor de la vulnerabilidad humana. Es aquí donde la escuela cobra un mayor protagonismo como pusieron de manifiesto los trabajos desarrollados por el grupo Gea-Clío en los años noventa en la región valenciana (Morote y Souto, 2020). Souto et al. (2019) señalan que en la explicación de las inundaciones en los manuales escolares se sigue reproduciendo el esquema clásico y obsoleto del ciclo de erosión de Davis de finales del s. XIX. Evidenciando, asimismo, que en muy pocos se cita la acción antrópica en la afección del régimen natural de los ríos. 
El visor del PATRICOVA es una herramienta eficaz y muy sencilla para poder implementar en las aulas e incluso adaptar estas sesiones a otros niveles inferiores (Educación Primaria y ESO). Además, estas sesiones se complementan con el uso de otros recursos y fuentes como son el INE, IGN, AEMET o portales de prensa digital que, son competencia que deben tratarse en las aulas como pone de manifiesto el Real Decreto (competencia digital). En cuanto a los contenidos aquí propuestos, no hay que olvidar que esta temática es recurrente, por ejemplo, en las Pruebas de Acceso a la Universidad. Por ejemplo, en la prueba de la Com. Valenciana de la convocatoria de julio de 2019, uno de los ejercicios fue "explica los principales riesgos naturales relacionados con los ríos que afectan en España" (Generalitat Valenciana, 2021).

La creciente movilización de estudiantes en aspectos relacionados con la crisis climática parece indicar una mayor conciencia por parte de la población en esta franja de edad que, sin duda, será clave en la consecución de una sociedad mejor adaptada a los escenarios futuros de cambio climático. Pero estas movilizaciones deben estar fundadas en un conocimiento adecuado de aspectos ambientales y climáticos que deben aprenderse en el aula. El desarrollo de materias sobre cambio climático y sus extremos atmosféricos contempladas en la recién aprobada Ley de Educación (Ley 3/2020, de 29 de diciembre) (LOMLOE), puede crear un marco idóneo de aprendizaje en esta temática, en los niveles no universitarios. Sin olvidar, como indican Morote y Olcina (2020), que la información sobre esta temática aún es escasa y quizá, sea necesario repensar el currículum de Ciencias Sociales y Geografía para dedicar una mayor atención y rigor científico a estos contenidos con la apuesta de una mayor y mejor formación del profesorado (actual y futuro) y no tanto la creación de nuevas asignaturas como manifestó la ministra de Educación tras la Cumbre del Clima (COP25) celebrada en Madrid (diciembre de 2019).

Como finalizar, y como propuesta de futuro, se plantea la necesidad de promocionar estas propuestas didácticas, tanto en el profesorado de Geografía en activo, como en formación (Máster de Formación del Profesorado de Secundaria y Bachillerato). En definitiva, se trata de material docente cuyo conocimiento en territorios de afección tienen por objeto fomentar una cultura del riesgo, una concienciación y sensibilización sobre los distintos elementos de peligrosidad y vulnerabilidad. Por tanto, es un reto importante que debe permitir, a través de la educación en valores territoriales y ambientales, crear sociedades más resilientes frente a los peligros de la naturaleza, cuyo efecto futuro se estima más perjudicial en el marco del proceso actual de cambio climático.

\section{Recursos en línea referenciados para usar en el Aula}

Adaptecca. Portal oficial de modelización del cambio climático en España: $\mathrm{http} / /$ escenarios.adaptecca.es/\#\& model $=$ multimodel\&variable $=$ tasmax \&scenario $=r c p$ 85\&temporalFilter $=$ YEAR\&layers $=$ AREAS\&period $=$ MEDIUM_FUTURE\&ano maly=RAW_VALUE 
AEMET. Agencia Estatal de Meteorología. Escenarios de cambio climático: http://www.aemet.es/es/serviciosclimaticos/cambio_climat/result_graficos

Confederación Hidrográfica del Segura. Aforos:

http://chsegura.es/chs/cuenca/redesdecontrol/estadisticashidrologicas/visoraforos/viso rjs.html

Confederación Hidrográfica del Segura (DHS) (2020a): Cronología de riadas en la cuenca del río Segura (1259-2012)" Ministerio para la Transición Ecológica y el Reto Demográfico:

https://www.chsegura.es/chs/informaciongeneral/elorganismo/unpocodehistoria/ri adas.html.

Confederación Hidrográfica del Segura (DHS) (2020b): Sistemas Automáticos de Información Hidrológica (SAIH). Ministerio para la Transición Ecológica y el Reto Demográfico: https://www.chsegura.es/chs/cuenca/redesdecontrol/SAIH/

Diario Información (1946-2019). Hemeroteca: https://www.informacion.es/hemeroteca/ https://biblioteca.ua.es/es/encuentra-informacion/recursos-e/prensa-digital.html https://afondo.informacion.es/temas/hemeroteca/

Instituto Cartográfico Valenciano: https://icv.gva.es/va/

PATRICOVA (visor web): https://visor.gva.es/visor/

Wetterzentrale. Portal de información meteorológica. Archivo de situaciones atmosféricas: https://www.wetterzentrale.de/es/reanalysis.php?model=cfsr

\section{Referencias bibliográficas}

Adam, B., Beck, U., y Van Loon, J. (2000): The Risk Society and Beyond: Critical Issues for Social Theory. London, Sage.

Ahmad, S., y Numan, S.M. (2015): Potentiality of disaster management education through open and distance learning system in Bangladesh open university. Turkish Online Journal of Distance Education, 16 (1), 249-260.

Bosschaart, A., Van der Schee, J., y Kuiper, W. (2016): Designing a flood-risk education program in the Netherlands. Journal of Environmental Education, 47(4), 271-286.

Bricelj, M. (2013): Kranjska stena - An example of good school practice. Geografija v Soli, 22 (2-3), 51-56.

Brisman, A. (2018): Representing the "invisible crime" of climate change in an age of posttruth. Theoretical Criminology, 22(3), 468-491.

Canales, G. (dir.) (1995): El Bajo Segura. Estructura espacial, demográfica y económica. Alicante, CAM Fundación Cultural; Universidad de Alicante. 
Centre for Research on the Epidemiology of Disasters (CRED) (2019): Economic Losses, Poverty \& Disasters (1998-2017). https://www.emdat.be/, consultado el 11 de mayo de 2020.

Chang, C. H., y Pascua, L. (2017): The curriculum of climate change education: A case for Singapore. The Journal of Environmental Education, 48(3), 172-181.

Chang, C. H., Irvine, K., Wu, B. S., y Seow, T. (2018): Reflecting on field-based and technology-enabled learning in geography. En Learning geography beyond the traditional classroom. Springer, 201-212.

Cuello, A. (2018): Las Inundaciones del invierno 2009-2010 en la prensa, un recurso educativo para las ciencias sociales. Revista de Investigación en Didáctica de las Ciencias Sociales, 2, 70-87.

Cuello, A., y García, F.F. (2019): ¿Ayudan los libros de texto a comprender la red fluvial de la ciudad? Revista de Humanidades, 37, 209-234.

Diario Las Provincias (15 de septiembre de 2019): La gota fría más violenta en 140 años se cobra otra vida y el Segura no cede- https://www.lasprovincias.es/comunitat/peor-gotafria-20190915004156-ntvo.html?ref=https \%3A\%2F\%2Fwww.bing.com $\% 2 \mathrm{~F}$

Díez-Herrero, A. (2015): Buscando riadas en los árboles: Dendrogeomorfología. Enseñanza de las ciencias de la tierra: Revista de la Asociación Española para la Enseñanza de las Ciencias de la Tierra, 23 (25), 272-285.

Duman, N. (2018): Determination of Misconceptions in Disaster Education with Concept Cartoons: The Case of Flood and Overflow. International Journal of Environmental \& Science Education, 13 (10), 831-843.

EM-DAT (2021): EM-DAT Query Tool. The International Disasters Database. Centre for Research on the Epidemiology of Disasters (CRED). https://public.emdat.be/data

Gary, G., Allred, S., y Lo Giudice, E. (2014): An extension education program to help local governments with flood adaptation. Journal of Extension, 52 (4), 4IAW6.

Garzón, G., Ortega, J.A., y Garrote, J. (2009): Las avenidas torrenciales en cauces efímeros: ramblas y abanicos aluviales. Enseñanza de las Ciencias de la Tierra, 17 (3), 264-276.

Generalitat Valenciana (2020). Plan Vega Rehace. Una estrategia integral para la resiliencia de la comarca de la Vega Baja del Segura. Valencia, Dirección General de Análisis y Políticas Públicas. http://www.presidencia.gva.es/es/web/vega-renhace

Generalitat Valenciana (2021). Pruebas de acceso de años anteriores. https://innova.gva.es/va/web/universidad/informacion-guias-y-pruebas-de-acceso-de-anosanteriores

Giddens, A. (1977): El capitalismo y la moderna teoría social. Barcelona, Labor, reed.

Gil, A., y Olcina, J. (2017): Tratado de Climatología. Alicante, Publicaciones de la Universidad de Alicante.

Gobierno de España (2021): Ley 7/2021, de Cambio Climático y Transición Energética. BOE núm. 121, de 21 de mayo de 202. https://www.boe.es/diario_boe/txt.php?id=BOE-A-20218447

How, V., Azmi, E. S. B., Zaki, N. F. B. M., y Othman, K. B. (2017): Integrating Flood Education Miniature and Interactive E-Learning in a Prototype of Flood Learning Kit for Knowledge Resilience Among School Children. En International Expert Forum: Mainstreaming Resilience and Disaster Risk Reduction in Education, Springer, 355-368. 
Intergovernmental Panel on Climate Change (IPCC) (2014): Climate Change 2013 and Climate Change 2014 (3 vols.). http://www.ipcc.ch/

Intergovernmental Panel on Climate Change (IPCC) (2018): Special Report Global warming of $1.5^{\circ} \mathrm{C}$. https://www.ipcc.ch/report/sr15/.

Irvine, K. N., Seow, T., Leong, K. W., y Cheong, D. S. I. (2015): How high's the water, Mama? A reflection on water resource education in Singapore. HSSE Online, 4(2), 128162.

Lechowicz, M., y Nowacki, T. (2014): School education as an element of natural disaster risk reduction. Prace i Studia Geograficzne, (55), 85-95.

Lee, Y., Kothuis, B.B., Sebastian, A., y Brody, S. (2019). Design of transformative education and authentic learning projects: Experiences and lessons learned from an international multidisciplinary research and education program on flood risk reduction. ASEE Annual Conference and Exposition, Conference Proceedings.

Luján, M., y García-Martínez, T. (2019): La riada de Santa Teresa de 1879. Una tragedia en la Huerta de Murcia. Cangilón, 36, 271-274.

McEwen, L., Stokes, A., Crowley, K., y Roberts, C. (2014): Using role-play for expert science communication with professional stakeholders in flood risk management. Journal of Geography in Higher Education, 38 (2), 277-300.

McWhirter, N., y Shealy, T. (2018): Case-based flipped classroom approach to teach sustainable infrastructure and decision-making. International Journal of Construction Education and Research, 16 (1), 1-21.

Meera, P., McLain, M. L., Bijlani, K., Jayakrishnan, R., y Rao, B. R. (2016): Serious game on flood risk management. In Emerging research in computing, information, communication and applications (197-206). Springer.

Ministerio del Interior (2020): Anuario Estadístico, 2019. Secretaría General Técnica. Madrid, http://www.interior.gob.es/documents/642317/1204854/Anuario+Estad\%C3\%ADstico+del +Ministerio+del+Interior+2019/81537fe0-6aef-437a-8aac-81f1bf83afla

Ministerio de Educación, Cultura y Deporte (2020): Real Decreto 126/2014, de 28 de febrero, por el que se establece el currículo básico de la Educación Primaria. Boletín Oficial del Estado. https://www.boe.es/buscar/pdf/2014/BOE-A-2014-2222-consolidado.pdf.

Morgan, A. (2012): Me as a Science Teacher': Responding to a Small Network Survey to Assist Teachers with Subject-Specific Literacy Demands in the Middle Years of Schooling. Australian Journal of Teacher Education, 37 (6). doi: 10.14221/ajte.2012v37n6.6

Morote, A.F. (2015): Transformaciones territoriales e intensificación de la demanda de agua urbano-turística en la provincia de Alicante. Tesis Doctoral. Universidad de Alicante.

Morote, A.F. (2017): El Parque Inundable La Marjal de Alicante (España) como propuesta didáctica para la interpretación de los espacios de riesgo de inundación. Didáctica Geográfica, 18, 211-230.

Morote, A.F., y Pérez-Morales, A. (2019): La comprensión del riesgo de inundación a través del trabajo de campo: Una experiencia didáctica en San Vicente del Raspeig (Alicante). Vegueta. Anuario de la Facultad de Geografía e Historia, 19, 609-631. 
Morote, A.F., y Hernández, M. (2020): Social Representations of Flooding of Future Teachers of Primary Education (Social Sciences): A Geographical Approach in the Spanish Mediterranean Region. Sustainability, 12 (15), 1-14. https://doi.org/10.3390/su12156065.

Morote, A.F., y Hernández, M. (2021): Water and Flood Adaptation Education: From Theory to Practice. Water Productivity Journal, 1(3), 31-40. doi: 10.22034/wpj.2021.264887.1025.

Morote, A. F., y Olcina, J. (2020): El estudio del cambio climático en la Educación Primaria: una exploración a partir de los manuales escolares de Ciencias Sociales de la Comunidad Valenciana”. Cuadernos Geográficos, http://dx.doi.org/10.30827/cuadgeo.v59i3.11792.

Morote, A.F., y Olcina, J. (2021): Cambio climático y sostenibilidad en la Educación Primaria. Problemática y soluciones que proponen los manuales escolares de Ciencias Sociales. Sostenibilidad: económica, social y ambiental, 3, 25-43. https://doi.org/10.14198/Sostenibilidad2021.3.02.

Morote, A.F., y Souto X. M. (2020): Educar para convivir con el riesgo de inundación. Estudios Geográficos, 81 (288), 1-14. https://doi.org/10.3989/estgeogr.202051.031.

Morote, A.F., Campo, B., y Colomer, J.C. (2021). Percepción del cambio climático en alumnado de $4^{\circ}$ del Grado en Educación Primaria (Universidad de Valencia, España) a partir de la información de los medios de comunicación. Revista Electrónica Interuniversitaria de Formación del Profesorado, 24(1), 131-144. DOI: https://doi.org/10.6018/reifop.393631.

Mudavanhu, C. (2015): The impact of flood disasters on child education in Muzarabani District, Zimbabwe. Jamba: Journal of Disaster Risk Studies, 6(1), 138.

Muñoz, C., Schultz, D., y Vaughan, G. (2020): A Midlatitude Climatology and Interannual Variability of 200- and 500-hPa Cut-Off Lows. Journal of Climate, 33(6), 2201-2222.

Murphy, A.B. (2018): Geografía. ¿Por qué importa?. Madrid, Alianza Editorial.

Olcina, J. (2017): La enseñanza del tiempo atmosférico y del clima en los niveles educativos no universitarios. Propuestas didácticas. En Sebastiá R. y Tonda, E.M. (Eds.). Enseñanza y aprendizaje de la Geografía para el siglo XXI. Universidad de Alicante, 119-148.

Olcina, J. (2018): Verdades y mentiras sobre el riesgo de inundaciones en el litoral mediterráneo: balance de medio siglo. Jornada sobre fenómenos meteorológicos extremos en el mediterráneo. 11 de diciembre de 2018. Valencia, AEMET.

Olcina, J., y Moltó, E.A. (2019): Climas y tiempos del País Valenciano. Alicante, Publicaciones de la Universidad de Alicante.

Olcina, J., Morote, A.F., y Hernández, M. (2018): Evaluación de los riesgos naturales en las políticas de ordenación urbana de los municipios de la provincia de Alicante. Legislación y $\begin{array}{lllll}\text { cartografía de riesgo. Cuadernos } & \text { 15eográficos, } 57 \text { (3), }\end{array}$ http://dx.doi.org/10.30827/cuadgeo.v57i3.6390.

Ollero, A. (1997): Crecidas e inundaciones como riesgo hidrológico. Un planteamiento didáctico.Lurr@1de, 20,261-283.

Ozdem, Y., Dal, B., Ozturk, N., Sonmez, D., y Alper, U. (2014). What is that thing called climate change? An investigation into the understanding of climate change by seventhgrade students. International Research in Geographical and Environmental Education, 23, 294-313. 
Pérez-Morales, A., Gil, S., y Quesada, A. (2021): Do we all stand equally towards the flood? Analysis of social vulnerability in the Spanish Mediterranean coast. Boletín de la Asociación de Geógrafos Españoles, 88, 1-39. https://doi.org/10.21138/bage.2970

Plan de Acción Territorial sobre Prevención del Riesgo de Inundación en la Comunitat Valenciana (PATRICOVA) (2015): http://www.habitatge.gva.es/es/web/planificacionterritorial-e infraestructura-verde/patricova-docs., consultado el 20 de febrero de 2020.

Rozada, J. Ma . (1997): Formarse como profesor. Ciencias Sociales, Primaria y Secundaria Obligatoria. Madrid, Akal.

Shah, A. A., Gong, Z., Ali, M., Sun, R., Naqvi, S. A. A., y Arif, M. (2020): Looking through the Lens of schools: Children perception, knowledge, and preparedness of flood disaster risk management in Pakistan. International Journal of Disaster Risk Reduction, 50, 101907.

Souto, X.M., Morote, A.F., y García, D. (2019): Crisis y riesgos naturales en la educación social. El caso del riesgo de inundación en Educación Primaria. En AGE y Universidad de Valencia. Crisis y espacios de oportunidad. Retos para la Geografía, Valencia, Universidad de Valencia, 171-185.

United Nations (2015): Sustainable Development Goals. UNDP, Sustainable Development Agenda. $\quad$ https://www.undp.org/content/undp/es/home/sustainable-developmentgoals/resources.html.

Ward, P.J. et al. (2020): Review article: Natural hazard risk assessments at the global scale. Nat. Hazards Earth Syst. Sci., 20, 1069-1096. https://doi.org/10.5194/nhess-20-10692020.

White, G. F. (1974): Natural hazards, local, national, global. United Kingdom: Oxford University Press.

Williams, S., McEwen, L. J., y Quinn, N. (2017): As the climate changes: Intergenerational action-based learning in relation to flood education. The Journal of Environmental Education, 48(3), 154-171.

Wisner, B., Blaikie, P., Cannon, T., y Davis, I. (2004): At risk. Natural hazards, people's vulnerability, and disasters. London and New York, Routledge.

Wetterzentrale (2020): Archivo. Reanálisis CFSR (1979-Actualidad). https://www.wetterzentrale.de/es/reanalysis.php? model $=\mathrm{cfsr}$

Zhong, S., Cheng, Q., Zhang, S., Huang, C., y Wang, Z. (2021): An impact assessment of disaster education on children's flood risk perceptions in China: Policy implications for adaptation to climate extremes. Science of the total environment, 757, 143761. doi: 10.1016/j.scitotenv.2020.143761 